BULLETIN Bulletin hispanique

HISPANIQUE Université Michel de Montaigne Bordeaux

$112-2$ | 2010

Varia

\title{
Le barde et le bouffon
}

La geste burlesque à l'époque de Lope de Vega

Samuel Fasquel

\section{(2) OpenEdition}

Journals

Édition électronique

URL : http://journals.openedition.org/bulletinhispanique/1228

DOI : 10.4000/bulletinhispanique.1228

ISSN : 1775-3821

Éditeur

Presses universitaires de Bordeaux

Édition imprimée

Date de publication : 31 décembre 2010

Pagination : 587-632

ISBN : 978-2-86781-709-0

ISSN : 0007-4640

Référence électronique

Samuel Fasquel, « Le barde et le bouffon », Bulletin hispanique [En ligne], 112-2 | 2010, mis en ligne le

05 janvier 2014, consulté le 20 avril 2019. URL : http://journals.openedition.org/

bulletinhispanique/1228; DOI : 10.4000/bulletinhispanique.1228 


\title{
Le barde et le bouffon. La geste burlesque à l'époque de Lope de Vega
}

\author{
Samuel Fasquel \\ CLEA (Paris IV)
}

La Gatomaquia de Lope de Vega, La Moschea de Villaviciosa et le Poema heroico de las necedades y locuras de Orlando el enamorado de Quevedo constituent un corpus poétique qui réunit les meilleurs fruits produits par la geste burlesque dans l'Espagne du Siècle d'or. Cet article analyse les profondes différences esthétiques qui caractérisent ces ceuvres dans le but de montrer que, malgré ces différences et en dépit de l'importance des éléments carnavalesques et grotesques, ces trois poèmes ne proposent nullement une inversion totale de l'ethos et de la rhétorique des héros.

La Gatomaquia de Lope de Vega, La Moschea de Villaviciosa y el Poema heroico de las necedades y locuras de Orlando el enamorado de Quevedo forman un corpus poético que ilustra lo mejor de la épica burlesca en la España del Siglo de Oro. El presente articulo analiza las profundas diferencias estéticas que caracterizan cada una de estas tres obras para mostrar que, pese a dichas diferencias y a la importancia de los elementos carnavalescos y grotescos, la épica burlesca dista de proponer una inversión total del ethos $y$ de la retórica de los héroes.

Lope de Vega's Gatomaquia, Villaviciosa's Moschea and Quevedo's Poema heroico de las necedades y locuras de Orlando el enamorado form a poetic corpus in which are found the best lines ever written in the burlesque epic genre during Spain's Golden Century. This article analyses the great aesthetic differences that characterize these works, in order to show that, despite these differences and the importance of the ludicrous and grotesque elements, these three poems do not offer a total inversion of the ethos and rhetoric of heroes.

Mots-clés : Burlesque - Épopée - Parodie - Lope de Vega - Quevedo, Villaviciosa.

Bulletin Hispanique, Tome 112, nº 2 - décembre 2010 - p. 587 à 632. 
T E célèbre traité de poétique dans lequel Ignacio de Luzán, en 1737, L examinait la littérature espagnole des époques qui l'avaient précédé ${ }^{1}$ ne pouvait faire l'économie de quelques commentaires sur le registre burlesque, dont les meilleurs fruits furent cultivés au dix-septième siècle. Si la poésie burlesque inspira de nombreux auteurs, elle suscita en revanche peu de réflexions érudites, et les propos de Luzán n'en sont que plus précieux. Dans un chapitre consacré aux différents procédés qui suscitent le rire (Capitulo $\mathrm{XX}$, Del estilo jocoso), il relève l'existence d'une littérature fondée sur l'inadéquation du contenu du poème et du registre de l'énonciation :

A la deformidad propia o ajena puede reducirse y atribuirse otro principio de nuestra risa y otra rama y especie de estilo jocoso, que consiste en la desproporción, desconformidad y desigualdad del asunto respecto de las palabras y del modo, o al contrario de las palabras y del modo respecto del asunto, y por este medio viene a ser muy apreciable en lo burlesco lo que sería muy reprensible en lo serio. Lo primero sucede cuando se hacen asunto y objeto principal de un poema los irracionales más viles y ridiculos o también hombres muy bajos y menospreciables por su estado y por sus cualidades; y a éstos, ya irracionales, ya hombres despreciables, se atribuyen acciones y palabras propias de hombres grandes y de héroes famosos. Lo segundo sucede cuando, por el contrario, se atribuyen acciones plebeyas, palabras y modos bajos a héroes y personas de gran calidad. De esta especie de graciosidad es la Batracomiomaquia, o sea la guerra entre ranas y ratones, célebre poema de Homero, a cuya imitación se han escrito después con extremada gracia la Gatomaquia, de Murguillos (sic); la Mosquea, de Villaviciosa, y otros; en Italia se celebra mucho la Secchia Rapita, de Tassoni, y el Orlando, de Berni, cuyas huellas quiso seguir nuestro don Francisco Quevedo en su Orlando, poema que quedó solamente empezado, con harto sentimiento de las Musas. De este género es también la Eneida en lengua napolitana, obra graciosisima para los que entienden bien aquel idioma ${ }^{2}$.

1. Sur la Poética de Luzán et le mélange de critique et d'admiration que suscitent chez lui les grands auteurs du dix-septième siècle, consulter Isabel M. Cid de Sirgado et Gabriela Makoviecka, "La Poética : doctrina e influencia ", dans Francisco Rico et José Miguel Caso González (sous la dir. de), Historia y crítica de la literatura española. 4. Ilustración y Neoclasicismo, Barcelona, Crítica, 1983, p. 163-171. Luzán est également l'auteur d'une Giganteida éditée et analysée par Aurora Egido dans « La Giganteida de Ignacio de Luzán. Argumento y octavas de un poema inédito ", Anales de Literatura Española, 2, 1983, p. 197-231.

2. Ignacio de Luzán, La Poética (ediciones de 1737 y 1789), Isabel M. Cid de Sirgado (éd.), Madrid, Cátedra, 1974, p. 237-238. 
Luzán distingue ici deux modalités d'une même espèce caractérisée par ce qu'il appelle la "desproporción ", la " desconformidad ", la "desigualdad", procédés analogues à la "disconvenance » que Perrault avait placée au cœur de sa définition du burlesque français ${ }^{3}$. Comme le fera plus tard Luzán, Perrault déclarait que " cette disconvenance se fait en deux manières, l'une en parlant bassement des choses les plus relevées, et l'autre en parlant magnifiquement des choses les plus basses». Les deux œuvres choisies par Perrault pour illustrer ces procédés étaient le Virgile Travesti, de Scarron, et le Lutrin, de Boileau. Luzán cite trois œuvres espagnoles construites sur cette " disconvenance ", sans toutefois préciser à quelle modalité correspond chaque exemple. $L a$ Gatomaquia et la Moschea illustrent la première ("cuando se hacen asunto y objeto principal de un poema los irracionales más viles y ridiculos»), tandis que le Poema heroico de las necedades y locuras de Orlando el enamorado présente un exemple de la seconde (" cuando, por el contrario, se atribuyen acciones plebeyas, palabras y modos bajos a héroes y personas de gran calidad "). Il s'agit toujours de cette littérature au second degré examinée par Gérard Genette. Mais, par ailleurs, si l'on adopte la classification du même critique, les deux épopées animalières que sont la Gatomaquia et la Moschea appartiennent au genre héroï-comique puisque leurs auteurs pastichent l'épopée ${ }^{4}$. En revanche, le poème de Quevedo constitue un exemple de travestissement burlesque, une réécriture comique de l'Orlando Innamorato de Boiardo. Regrouper toutes ces œuvres sous une même rubrique en considérant que toutes relèvent de la disconvenance masque une différence qui n'est pas mince. Dans les poèmes héroï-comiques, l'auteur prétend offrir une épopée dont il invente un contenu qui va en partie à rebours des normes épiques établies par les traités ou l'usage poétiques. Il en va ainsi, par exemple, dans la Batrachomyomachie, poème consacré à une guerre de rats et de grenouilles ${ }^{5}$, et de manière générale dans toutes les épopées animalières. Mais il en va de même dans la Secchia Rapita, dont les personnages luttent pour la possession d'un vulgaire seau (" un'infelice e vil secchia di legno », I, 1, v. 3) enlevé par les

3. Charles Perrault, Parallèle des Anciens et des Modernes, Paris, chez J. B. Coignard, 16881697 (consulter t. 3, 1692, p. 291-303).

4. Gérard Genette, Palimpsestes. La littérature au second degré, Paris, Seuil, 1982, p. 191192. Sur la parodie, on consultera l'important article de Silvia Longhi, «Propagata voluptas: Henri Estienne et la parodie ", Bibliothèque d'Humanisme et Renaissance, 47-3, 1985, p. 595608.

5. «La Batrachomyomachie (Le Combat des rats et des grenouilles), attribuée à Homère, mais en fait postérieure de deux ou trois siècles, montre les Olympiens passionnés par les péripéties d'une guerre animalière : satire des dispositifs rhétoriques disponibles pour "ennoblir" tout sujet, d'une emphase qui élève tout incident à la dignité de crise cosmique [...] ", Daniel Madelénat, L'Épopée, Paris, PUF, 1986, p. 189. 
habitants de Modène à ceux de Bologne. Le locuteur héroï-comique raconte des aventures qui relèvent d'un univers poétique étranger à l'épopée tout en cherchant à se hisser à la hauteur de l'aède antique. En revanche, dans le cas du Poema heroico de las necedades y locuras de Orlando el enamorado ou du Virgile Travesti, Quevedo et Scarron s'inspirent directement du monde de l'épopée tel que l'illustrent le Roland Amoureux ou l'Énéide pour mieux souligner ce qui, dans l'univers qu'ils créent, ne peut constituer un héritage épique. Ils s'emploient à rendre manifeste le discours du bouffon, étranger aux chefs d'œuvre qu'ils travestissent, connus et immédiatement reconnus du lecteur. L'art du travestissement réside ainsi dans la capacité du poète à se détacher de l'œuvre travestie tout en obtenant qu' elle soit immanquablement reconnaissable sous ses traits grimaçants, tandis que l'art du poète héroïcomique tient dans l'habileté avec laquelle il parvient à revêtir le masque du poète épique malgré le prosaïsme de son argument ou la vulgarité de ses personnages.

Les trois poèmes espagnols cités par Luzán illustrent donc des pratiques différentes de l'intertextualité. Toutefois, la diversité de ces œuvres n'est pas telle qu'elles appartiennent à des provinces littéraires étrangères. Les poèmes de Villaviciosa, Lope de Vega et Quevedo constituent un corpus susceptible d'être étudié comme tel parce qu'ils impliquent tous une adaptation ludique des éléments constitutifs du canon épique. De surcroît, chacun de ces poèmes illustre un projet ambitieux qui ne se borne pas à travestir un épisode célèbre mais s'attache à écrire une épopée dans son intégralité. Certes, le poème de Quevedo resta inachevé, néanmoins les quelque mille sept-cents vers qui nous sont parvenus laissent supposer que l'auteur voulait réécrire l'ensemble du poème de Boiardo. Enfin, ces trois poèmes sont presque contemporains, leur rédaction datant du premier tiers du dix-septième siècle. Pour toutes ces raisons, ce sont ces trois œuvres, les seuls poèmes espagnols que cite Luzán pour illustrer le principe de disconvenance, que je vais retenir dans cette étude de la geste burlesque à l'époque de Lope de Vega.

Pour Luzán, La Moschea, le Poema Heroico de la necedadesylocuras de Orlando el enamorado et La Gatomaquia illustrent tous un même style. Néanmoins, le mélange des voix burlesque et épique confère à l'énonciation des accents variables d'un poème à l'autre. Je voudrais montrer que cette diversité correspond à trois projets littéraires distincts mais dont aucun ne donne lieu à ce que l'on pourrait appeler une anti-épopée glissant vers l'anti-héroïsme. Bien au contraire, Villaviciosa, Lope et Quevedo prêtent à leurs personnages l'ethos et la rhétorique des héros. Pour réaliser cette démonstration, je vais d'abord m'intéresser aux matériaux poétiques constitutifs de ces poèmes ainsi qu'à leur construction et au rapport qu'ils entretiennent avec le genre 
épique. Je m'attarderai ensuite sur les caractéristiques de l'énonciation en montrant que si, dans chaque poème, le lecteur entend les voix du barde et du bouffon, cette polyphonie prend à chaque fois une forme différente qui nous renseigne sur le projet littéraire de nos poètes. Il sera alors possible d'étudier ce que les personnages doivent aux héros épiques et chevaleresques, et d'en déduire, pour conclure, la place qu'il faut reconnaître à la geste burlesque dans la trajectoire de l'épopée.

\section{UNE GESTE BURLESQUe}

Les poèmes de Villaviciosa, Lope de Vega et Quevedo montrent chez leurs auteurs la maitrise parfaite des procédés structurels et stylistiques inhérents à l'épopée. Villaviciosa et Lope de Vega mettent en œuvre un arsenal narratif typique : après la propositio et l'invocation des muses le lecteur découvre un récit avec ses héros et leurs combats, ses interventions divines, ses descriptions et digressions, ses comparaisons épiques, ses harangues ${ }^{6}$. Quevedo reprend lui aussi une part importante de cet arsenal, déjà présent dans son hypotexte. Avant d'approfondir l'étude de la polyphonie dans ces poèmes, une présentation analytique permettra de déterminer si c'est le modèle de l'epos ou celui du romanzo $0^{7}$ qui se prête le mieux à l'écriture de la geste burlesque.

L'argument du premier poème publié, La Moschea de Villaviciosa (1615), est le suivant. Cinq cents ans après la création de la ville de Moschea, dans les Pouilles, le roi des mouches, Sanguileón, décide d'organiser un grand

6. Consulter l'introduction de Celina Sabor de Cortázar à Lope de Vega, La Gatomaquia, Madrid, Castalia, 1983, p. 24-33, et celle de Ángel Luis Luján Atienza à José de Villaviciosa, La Moschea. Poética inventiva en octava rima, Cuenca, Diputación de Cuenca, 2002, p. 2545. Ces deux ouvrages seront nos éditions de référence. Pour éviter d'alourdir les notes, nous ne les mentionnerons désormais qu'à travers le titre. Il en ira de même pour les sonnets de Lope, cités à partir de Lope de Vega, Rimas humanas y divinas del licenciado Tomé de Burguillos, Jesús Cañas Murillo et Juan Manuel Rozas (éds.), Madrid, Castalia, 2005. Le lecteur tirera également profit de l'édition réalisée par Antonio Carreño (Salamanca, Almar, 2002), qui offre l'intégralité des Rimas humanas y divinas, et examine attentivement la dimension parodique du recueil.

7. Sur cette question, voir Torquato Tasso, Discorsi dell'arte poetica e del poema eroico, Luigi Poma (éd.), Bari, Laterza, 1964. Pour la critique, Maxime Chevalier, L'Arioste en Espagne (1530-1650). Recherches sur l'influence du "Roland Furieux ", Bordeaux, Institut d'études ibériques et ibéro-américaines, 1966 ; José Lara Garrido, Los mejores plectros. Teoría y práctica de la épica culta en el Siglo de Oro, Málaga, Universidad de Málaga, 1999; Sergio Zatti, Il Furioso fra epos e romanzo, Lucca, Maria Pacini Fazzi editore, 1990; Sergio Zatti, L'ombra del Tasso. Epica e romanzo nel Cinquecento, Milano, Mondadori, 1996. 
tournoi dont le vainqueur recevra la main de l'Infante. Peu avant l'ouverture des festivités, un messager informe le monarque du péril qui le menace : les fourmis complotent contre les mouches et veulent rallier tous leurs ennemis. Elles ont déjà décimé sept mille mouches et fait prisonnier le fils de Sanguileón. Le souverain, abattu par la nouvelle, obtient rapidement l'appui de son beau-frère, Matacaballo, roi des taons, dont le discours provoque en Sanguileón un véritable sursaut épique. Les mouches prennent la mer en direction du royaume des fourmis, accompagnées par les taons, les moustiques et les fourmilions. Mais leurs troupes essuient une terrible tempête pendant la traversée et font naufrage. Elles parviennent à rejoindre le rivage ennemi, sans l'un des principaux champions du camp des mouches, Sicaborón. Ce dernier finit par gagner à son tour la terre ferme, et, après avoir livré combat avec quelques puces manquant aux plus élémentaires règles de la chevalerie, il rejoint les siens. De leur côté, les fourmis fourbissent leurs armes. Le roi, Granestor, a réuni derrière ses troupes les araignées, les punaises, les poux et les puces. L'un des chefs du camp des mouches, Asinicedo, vient lancer à l'ennemi le défi qui déclenchera la guerre totale entre les deux camps. Les derniers chants sont consacrés à ces combats qui voient la mort de Sanguileón puis de Sicaborón, et la victoire du camp des fourmis.

Divisée en douze chants et comptant plus de huit mille vers, La Moschea s'inspire ouvertement d'un poème de Folengo intitulé Moscheide ${ }^{8}$. Mais Villaviciosa délaisse le style macaronique de Folengo et crée à partir du poème italien une œuvre nouvelle, laissant libre cours à son imagination et procédant par amplifications ${ }^{9}$. Villaviciosa emprunte également à l'Enéide ${ }^{10}$. Son récit est linéaire, le lecteur découvre les origines de la ville (chant I), les exactions auxquelles se livrent les fourmis et la réaction du roi

8. Voici ce que l'on peut lire dans l'histoire de la littérature italienne de Cesare Segre et Clelia Martignoni, Testi nella storia. La letteratura italiana dalle origini al novecento, 2, Edizioni Scolastiche Bruno Mondadori, 1992, p. 414: « Nel 1517 apparve a Venecia la prima edizione delle Maccheronee. L'autore si celava sotto lo pseudonimo [...] di Merlin Cocai. A quel tempo il Folengo soggiornava forse nel monasterio di Santa Giustina a Padova, nella città dove il latino maccheronico era nato per burlesca iniziativa dell'ambiente studentesco. [...] Folengo vuole provare che quello speciale linguaggio è applicabile a generi ben diversi ma tutti di illustre tradizione: il Baldus [...] è il corrispettivo maccheronico del poema epico ; la Zanitonella, il corrispettivo dell'egloga; la Moscheide, il corrispettivo del poema eroicomico, alla maniera della pseudo-omerica Batracomiomachia [...]"

9. Ángel Luis Luján écrit: «Nadie puede negar que el hilo argumental de la obra de Villaviciosa está tomado de Folengo [...] Sin embargo, a simple vista se comprueba que Villaviciosa enriquece los episodios con la técnica amplificativa [...] hasta hacer un poema casi siete veces más extenso que su original ", La Moschea, p. 64.

10. La Moschea, p. 54-57. 
Sanguileón (chants II et III), la traversée périlleuse vers le royaume ennemi et les premières escarmouches (chants IV-V-VI) ; le chant VII est consacré aux origines mythiques de la haine que se vouent les deux camps, et à la description de l'armée des fourmis ; les chants VIII et IX présentent les réactions des dieux ; les trois derniers chants narrent le combat final et la défaite des mouches. Il n'y a guère de place pour l'amour dans ce poème, alors que Villaviciosa, en offrant au vainqueur du tournoi la main de l'infante, détenait la clé de possibles développements narratifs. Il n'exploite pas cette possibilité, évitant de trop s'éloigner du fil principal de sa trame narrative. Certes, les digressions ne manquent pas. L'éditeur de La Moschea, Ángel Luis Luján Atienza, lit dans ces digressions une forme d'humour et de jeu avec les normes littéraires, Villaviciosa attribuant une place centrale dans le poème à ce que les théoriciens considèrent marginal. Le premier et le huitième chants, consacrés respectivement aux origines de la ville et à la description de l'Enfer, constituent ce que Luján Atienza appelle des "chants digressions $"{ }^{11}$. Ces digressions interrompent le déroulement $\mathrm{du}$ récit, elles le retardent et d'aucuns jugeront qu'elles l'alourdissent. Toutefois, elles ne constituent nullement des excroissances parasitant le récit principal, qu'au contraire elles servent. Ainsi, la matière de ces digressions, souvent mythologique, plonge le lecteur dans un univers qui est celui des origines du combat qui oppose les mouches aux fourmis (chant VII). Ces dernières naquirent du sang répandu par la dépouille du serpent Python, tué par Apollon. Depuis, du sang des animaux morts renaissent les fourmis. Or, les mouches se nourrissent des dépouilles d'animaux, entravant ainsi le processus de reproduction des fourmis. C'est là l'origine de la haine séculaire que se vouent les deux camps :
Al fin, desde aquel punto, instante y hora
que de las moscas la progenie aleve
de la sangre corrupta engendradora

11. La Moschea, p. 37. Ángel Luis Luján considère que ce huitième chant représente un point d'inflexion dans l'œuvre, séparant les préparatifs de la guerre et les combats eux-mêmes. Pour l'interprétation morale qu'il donne de ce chant, consulter les pages 40-41 et 91-92. Par ailleurs, signalons que l'article qu'Aurora Egido a consacré à la Giganteida de Luzán analyse l'importance que cet auteur accorde à l'interprétation allégorique dans l'épopée. Sous ce rapport, la pratique poétique de Luzán et la théorie développée dans sa Poética sont parfaitement cohérentes ("La Poética recuerda que no sólo no eran, a juicio de Luzán, poemas épicos los que carecian de configuración alegórica, sino los que no implicaban instrucción moral, como La Dragontea de Lope o La Numantina de Francisco Mosquera. La lección formulada, añadida al proceder alegórico, daba, de este modo, pleno sentido épico a La Giganteida, frente a otras obras anteriores", op. cit., p. 210). 


\author{
del hormiga feroz el humor bebe, \\ desde aquel tiempo acá en los pechos mora \\ el rencor enemigo, que los mueve \\ a que en guerras campales se ejerciten \\ y unas con otras el vivir se quiten. (VII, vv. 233-240)
}

La guerre qui se trouve au cœur du poème est déclenchée par les exactions perpétrées par les fourmis, mais cette guerre n'est en fait qu'un épisode du conflit ancestral qui oppose les deux races et qui remonte au mythe du serpent Python ${ }^{12}$. Les digressions qui évoquent le Palais des Dieux ou la course du Soleil créent un décor mythique et en cela digne des causes ancestrales attribuées à la haine que les fourmis vouent aux mouches. Il en va de même du chant VIII, dans lequel Pluton insiste sur le caractère extraordinaire du massacre à venir, et du chant IX, qui raconte comment Jupiter envoya Mercure observer ce qui se passe sur Terre. Cet intérêt que les dieux d'en bas et d'en haut portent aux personnages principaux fait des fourmis et des mouches les jouets d'un destin qu'elles ne maîtrisent pas, et contribue à élever leurs combats au rang de l'épopée. Les digressions servent donc le récit en actualisant ce qui, dans les origines ancestrales du conflit, relève du mythe.

Par ailleurs, ces digressions ne transportent jamais le lecteur bien loin du récit principal. Quand, au huitième chant, Pluton ordonne que ses sujets s'apprêtent à recevoir de nombreuses âmes, il ne fait qu'annoncer les combats sanglants des derniers chants. Le neuvième chant s'ouvre par une digression sur le Palais de Jupiter et l'émoi suscité par les hostilités. Mais cette digression introduit un récit par lequel Mercure rend compte à Jupiter des préparatifs de la guerre. Il nous livre ainsi ce qui s'est produit pendant que Villaviciosa nous entraînait auprès de Pluton, tout en nous ramenant progressivement au cœur du conflit. Là encore, la digression n’a pas interrompu le récit de telle sorte que le lecteur en perde totalement le fil. De même, à l'ouverture du deuxième chant, la longue digression sur la course du soleil (vv. 1-136) ne fait que recréer dans l'espace du récit la distance qui doit séparer la fin du premier chant, consacré à la création du royaume des mouches, et le récit principal du deuxième chant, qui évoque le règne de Sanguileón, cinq cents ans plus tard. Les digressions participent donc harmonieusement à l'économie générale du récit. La matière du poème de Villaviciosa, comme son organisation, montrent qu'il écarte le modèle du romanzo. Cet auteur

12. Sur les causes ancestrales et les causes immédiates, voir les remarques de l'éditeur, p. 38. Voir également le chant X, vv. 657-664, qui inscrit ouvertement la guerre que les fourmis et les mouches vont se livrer dans le prolongement du mythe du serpent Python. 
privilégie un contenu et une forme plus proches de l'épopée classique, avec une notable prépondérance du thème guerrier sur le thème amoureux et le déroulement d'un récit qui ne repose pas sur le foisonnement d'épisodes entrelacés.

En revanche, La Gatomaquia, publiée une vingtaine d'années plus tard parmi les Rimas humanas y divinas del Licenciado Tomé de Burguillos $(1634)^{13}$, marque une influence plus nette de la matière du romanzo, mais point de sa forme. Contrairement à ce qui se produisait dans La Moschea, l'amour est au cœur du poème de Lope. La Gatomaquia raconte comment Marramaquiz, un chat amoureux de l'irrésistible Zapaquilda, est trahi par cette dernière, qui lui préfère les charmes de Micifuf. Le jour des noces qui doivent unir Zapaquilda et Micifuf, Marramaquiz, fou de rage, enlève la belle. Micifuf convoque le conseil des chats, qui décide d'assiéger la demeure de Marramaquiz. Ce dernier périt lors du siège, atteint accidentellement par le projectile d'un chasseur. Micifuf retrouve alors Zapaquilda et pardonne à ceux qui ont soutenu son ennemi.

Nous disposons de plusieurs articles ${ }^{14}$ sur ce poème qui semble directement inspiré des amours de Lope de Vega et Elena Osorio, amours contrariées par Francisco Perrenot de Granvela, tout comme Micifuf sème la zizanie entre Marramaquiz et Zapaquilda. Lope réécrit cette histoire vieille de cinquante ans et qui constitue l'argument d'autres œuvres, en particulier La Dorotea ${ }^{15}$. Par ailleurs, Felipe Pedraza a démontré que, dans la Gatomaquia, Lope suit les règles fixées dans son Arte nuevo de hacer comedias ${ }^{16}$. Le poème des chats a

13. La Gatomaquia semble avoir été rédigée peu avant la publication des Rimas humanas y divinas del Licenciado Tomé de Burguillos (Juan Manuel Rozas, Estudios sobre Lope de Vega, Madrid, Cátedra, 1990, p. 93).

14. J’ai pu consulter les articles suivants: Felipe Pedraza Jiménez, «La Gatomaquia, parodia del teatro de Lope ", dans Manuel Criado de Val (sous la dir. de), Lope de Vega y los orígenes del teatro español. Actas del I congreso internacional sobre Lope de Vega, Madrid, Edi-6, 1981, p. 565-580; Alberto Acereda, «Hacia una revalorización de La Gatomaquia», Anales de Filología Hispánica, 5, 1990, p. 183-190; José María Balcells, "La Gatomaquia : de la innovación al canon ", Edad de Oro, 14, 1995, p. 29-35; Manuel Fernández Nieto, "La Gatomaquia de Lope, de poema a comedia ", Edad de Oro, 14, 1995, p. 151-160. En revanche, je n'ai malheureusement pas pu me procurer l'article de Marcella Trambaioli, «El viejo Lope se divierte: parodia y sátira literaria en "La Gatomaquia" ", dans Maria Grazia Profeti (sous la dir. de), Per ridere. Il comico nei Secoli d'Oro, Firenze, Alinea, 2001, p. 183-209. Je renverrai également à plusieurs reprises à l'étude que Felipe Pedraza Jiménez a consacré à l'œuvre poétique de Lope (El universo poético de Lope de Vega, Madrid, Ediciones del laberinto, 2003). Lauteur examine avec finesse et précision la Gatomaquia et les Rimas de Tomé de Burguillos aux pages $215-240$.

15. Sur tout ceci voir l'introduction de C. Sabor de Cortázar.

16. Dans l'article précédemment cité, Felipe Pedraza déclare: «La Gatomaquia está escrita 
également retenu l'attention de Manuel Fernández Nieto, qui y voit le point culminant d'un processus de simplification des poèmes narratifs de Lope. Progressivement, ce dernier appliquerait à sa poésie narrative, et notamment épique, les règles propres au genre qu'il maitrise le mieux : la comedia. La Gatomaquia serait en quelque sorte une solution aux problèmes poétiques rencontrés par le Lope des épopées sérieuses ${ }^{17}$. Quant à José María Balcells, il situe La Gatomaquia dans le processus de constitution du canon héroïcomique, et considère qu'il s'agit de la première œuvre qui accorde une telle importance à la fois à l'épopée animalière de type homérique et à la parodie de la poésie chevaleresque ${ }^{18}$.

Celina Sabor de Cortázar, dans l'excellente introduction qu'elle rédigea pour son édition du poème, étudie ce que La Gatomaquia doit au poème épique. La guerre de Troie, avec l'enlèvement d'Hélène, ne pouvait qu'inspirer l'amant d'Elena Osorio. Il en va de même de la folie de Roland, modèle suivi par Lope dans l'épisode de la fureur jalouse de Marramaquiz. Pour l'éditrice, La Gatomaquia ne parodie pas pour autant les poèmes chevaleresques italiens, dont la construction labyrinthique demeure bien éloignée de celle du poème de Lope. Ce dernier doit surtout à l'Arioste le motif de la folie de Roland ${ }^{19}$. C. Sabor de Cortázar conclut son analyse en affirmant que Lope a recours aux procédés du poème épique, tant pour la forme que pour le contenu, et qu'il les met au service de la parodie en substituant les chats aux hommes. Par ailleurs, lorsqu'elle examine la proposition initiale, C. Sabor déclare : "Es claro que amor y desdén son el motivo del canto ; lo guerrero interviene

siguiendo al pie de la letra el Arte nuevo de hacer comedias. Su correspondencia con el drama lopesco es, a mi entender, tan exacta que no cabe dudar de la intención paródica, aunque cariñosa y juguetona, del Lope viejo que se ríe benévolamente del mozo que fue".

17. «[... [ La Gatomaquia es el final del proceso que emprende Lope con sus poemas narrativos. Estos, una vez abandonada su formulación culta, se van acercando más a la formulación que $\mathrm{El}$ Fénix mejor dominaba: la dramática. Es un proceso que inicia con $\mathrm{El}$ Isidro y concluye con el texto gatuno; a medida que sus versos se alivian de carga erudita, se aproximan más a la que habia de ser su mejor producción y, sin embargo, la menos considerada por el autor ». Manuel Fernández Nieto, op. cit., p. 159-160. Par ailleurs, le poème des chats a également été lu comme une attaque contre Pellicer et les poètes gongorisants (Rimas humanas y divinas del Licenciado Tomé de Burguillos, p. 45 et suivantes).

18. José María Balcells, op. cit..

19. La Gatomaquia, p. 19-20. Felipe Pedraza Jiménez écrit, aux pages $572-573$ de son article : "No se propuso una parodia estricta ni del poema épico, ni de la comedia española. Con libertad absoluta va elaborando una trama, unas situaciones y unos comentarios a las mismas que son, a un tiempo, remedo del mundo épico clásico-renacentista y del universo dramático de sus centenares de comedias. Mezcla elementos de distintas procedencias y crea un poema paródico que no se sujeta al pie forzado de caricaturizar punto por punto a un género o estilo [...] La parodia épico-dramática es risueña y está en las antípodas de la feroz sátira quevedesca ". 
en menor medida [...]» ${ }^{20}$, analyse confirmée d'ailleurs par la suite du récit. D'un point de vue strictement quantitatif, La Gatomaquia est un poème amoureux plutôt qu'épique. Si la guerre n'intervient que « dans une moindre mesure ", et si le modèle de la comedia s'avère déterminant, que doit au juste La Gatomaquia à l'épopée ? Le genre épique ne demeure-t-il somme toute qu'à l'état de réminiscence dans un poème dont l'interprétation devrait tenir compte avant tout d'autres genres littéraires?

En plaçant l'amour au cœur de son poème, Lope accorde une importance majeure à une matière parfaitement compatible avec le genre épique. Le Tasse considère la matière amoureuse comme un thème possible de l'épopée. Il cite l'exemple du poème de Héro et Léandre, épyllion écrit par Musée ${ }^{21}$. On connaît du reste la place considérable accordée à l'amour dans sa Jérusalem Délivrée. Lope lui-même avait par ailleurs écrit, avec La Hermosura de Angélica (1602), un poème que Marcella Trambaioli considère comme une "épopée amoureuse "22. Lope annonce dès l'ouverture de La Gatomaquia qu'il se propose de chanter la colère et le dédain que provoque l'amour :

\author{
Yo, aquel que en los pasados \\ tiempos canté las selvas y los prados, \\ éstos vestidos de árboles mayores \\ y aquéllas de ganados y de flores, \\ las armas y las leyes \\ que conservan los reinos y los reyes, \\ agora, en instrumento menos grave, \\ canto de amor suave \\ las iras y desdenes, \\ los males y los bienes, \\ no del todo olvidado \\ el fiero taratántara, templado \\ con el silbo del pifaro sonoro. (I, vv. 1-13)
}

20. Pour ces deux derniers commentaires, La Gatomaquia, p. 32 puis 28.

21. "Concedasi dunque che'l poema epico si possa formar di soggetto amoroso, com'e l'amor di Leandro e d'Ero, déquali cantò Museo, antichissimo poeta greco [...] ", Torquato Tasso, op. cit., p. 108. Françoise Graziani déclare : «Dans ses réflexions sur l'art poétique, le Tasse insiste beaucoup sur la nécessité pour le poète épique de se nourrir autant de Pétrarque que de Virgile, pour pouvoir donner à son œuvre l'intensité et la musicalité nécessaires à une œuvre totale et sublime. C'est pourquoi l'amour lui semble devoir être accepté parmi les thèmes obligés de l'épopée [...] ", (Le Tasse, La Jérusalem Délivrée, Françoise Graziani (éd.), Paris, Flammarion, 1997, p. 23).

22. Lope de Vega, La Hermosura de Angélica, Marcella Trambaioli (éd.), Madrid, Frankfurt Am Main, Iberoamericana, Vervuert, 2005, p. 65. Consulter également les pages 59-60. 
L'auteur part des premiers vers de l'Enéide ${ }^{23}$ puis s'en éloigne en faisant des armes, non pas la matière du poème à venir, mais celle de poèmes antérieurs. Le chant proprement épique est donc présenté comme un chant passé24. Le chant actuel, celui qui se trouve au cœur de la propositio, est plus léger, "menos grave ". Il ne s'agit pas d'un chant d'amour, mais d'un chant sur la colère que peut faire naître l'amour. Ici, Lope évoquera l'amour comme matière constitutive de l'épopée, la passion dans ce qu'elle a d'autodestructeur et surtout de destructeur pour la collectivité, lorsqu'elle entraîne la guerre de Troie, ou des combats entre les meilleurs chevaliers d'un même camp, qu'ils luttent pour les beaux yeux d'Angélique, de Doralice, d'Armide ou de Zapaquilda. Si, dans l'envoi aux muses, Lope annonce " canto / la guerra, los amores y accidentes / de dos gatos valientes " (I, vv. 16-18), c'est bien vers un conflit collectif opposant deux camps ennemis que le poème se dirige progressivement. Le sénat réuni autour de Micifuf pour décider du châtiment qu'il faut réserver à Marramaquiz se déclare favorable à l'avis de Raposo, qui souhaite lever une armée et partir en guerre :

que el mio [mi parecer] es juntar gente
para tan grave empresa, conveniente,
y formando escuadrones
de caballos y armada infantería
de toda la parienta gatería,
hacer guerra al traidor, cercar la tierra,

23. Celina Sabor de Cortázar indique en note aux vers 1-2: "imitación de la dedicatoria de la Eneida de Virgilio : Ille ego qui quondam gracili modulatus avena / carmen, et egressus silvis, vecina coegi... " (La Gatomaquia, p. 71). Dans l'édition de l'Enéide réalisée par Jacques Perret, on peut lire que les quatre vers qui figurent « avant le célèbre Arma virumque cano ont été conservés par Servius [...] et dans la Vita [...] comme le début authentique de l'Énéide. "Varius et Tucca" (ou "Varius" seul) les auraient éliminés, en suite de quoi ils manquent dans tous nos manuscrits" (Virgile, Énéide, Paris, Les Belles Lettres, 1977, p. 141). Dans $P$. Virgilii Maronis Opera, Mauri Servii honorati grammatici in eadem commentarii, ex antiquis exemplaribus suae integritati restituti (Paris, Ex officina Roberti Stephani, 1532) on peut lire: "Augustus vero ne tantum opus periret, Tuccam et Varum hac lege jussit emendare, ut superflua demerent, nil adderent tamen : unde et semiplenos ejus invenimus versiculos [...] Et aliquos detractos, ut in principio. Nam ab armis non incepit. Sed sic: Ille ego, qui quondam gracili modulatus avena /Carmen et egressus sylvis vicina coegi, /Ut quanvis avido parerent arva colono, / Gratum opus agricolis : at nunc horrentia Martis /Arma virumque cano".

24. Signalons également que le poème est dédié au fils de Lope, parti en guerre et qui saura se délasser à la lecture de La Gatomaquia (I, vv. 25-50). Cette présentation du poème comme texte devant offrir quelque repos au guerrier lorsque les armes se taisent n'est pas attachée à l'épopée, on ne trouve rien de semblable dans les exordes des poèmes de Boiardo, Arioste, le Tasse, Ercilla, Camóes, ni dans La Dragontea de Lope. 


\author{
$y$ asestándole tiros y cañones \\ batirle la muralla noche y dia \\ hasta saber qué gente le socorre \\ [...] \\ que así cobró su esposa en Troya el griego, \\ publicando la guerra a sangre y fuego. (VI, vv. 411-432)
}

La querelle qui, au départ, n'oppose que Marramaquiz à Micifuf dans une configuration analogue à celle des comedias, manque d'entraîner la disparition totale des chats, que seule l'intervention de Jupiter permet d'éviter. Craignant le triomphe de souris qui pourraient devenir de nouveaux Titans, Jupiter plonge les combattants dans une brume épaisse qui les contraint à interrompre les hostilités. C'est le début du siège, qui obligera Marramaquiz à tenter une sortie en quête de nourriture, expédition pendant laquelle il trouvera la mort. Le lyrisme du poème ne suffit donc pas à faire disparaittre l'épopée. Ainsi, l'amour, dans La Gatomaquia, est parfaitement compatible avec l'epos puisque les sentiments individuels déterminent le destin collectif en entraînant une guerre fratricide. Si les combats collectifs n’apparaissent véritablement qu’à la fin ("Perdona, Amor, que aqui comienza Marte ", VI, v. 442), plusieurs altercations émaillent le récit bien avant que la guerre soit déclarée. Dès la deuxième silva, le locuteur évoque le combat de Marramaquiz et d'un page de Micifuf, puis celui qui oppose Zapaquilda à Micilda. La silva suivante se termine sur le combat des deux chats ennemis, alors que la quatrième décrit un nouvel échange houleux entre Zapaquilda et Micilda. Par ailleurs, le locuteur compare souvent ses chats aux héros de l'Antiquité, Achille, Agamemnon, Pyrrhus, etc ${ }^{25}$. Le lecteur peut bien reconnaître des épisodes amoureux et une trame dignes de comédies de cape et d'épée, il n'en lit pas moins un poème qui renvoie ouvertement, dès son titre et ses premiers vers, à l'épopée antique : La Gatomaquia rappelle la Batrachomyomachie, et la proposition reprend celle de l'Énéide. Ces deux éléments constituent des indicateurs sémiotiques qui désignent le genre qui doit présider à l'interprétation du poème : l'épopée ${ }^{26}$. Bien sûr, ces signes n'empêchent pas Lope de recréer également un univers familier au lecteur de ses comedias, d'appliquer certaines règles propres à ce genre et d'annoncer un contenu qui ne se limitera pas à la matière première de l'épopée. Cette

25. Voir par exemple, La Gatomaquia, II, vv. 185, 197 ; III, vv. 221-222 (ici, l'identification est ouvertement ironique); V, vv. 300, 331, 336.

26. Sur l'interprétation d'un poème et de sa signifiance, Michael Riffaterre, Sémiotique de la poésie, Paris, Seuil, 1983. C'est en m’inspirant de cet ouvrage que je parlerai plus loin de plan sémiotique et de plan mimétique. 
attraction du modèle dramatique, examinée de façon tout à fait convaincante par C. Sabor, F. Pedraza et M. Fernández Nieto, ainsi que la part considérable accordée aux éléments romanesques, transparaissent indéniablement à la lecture du poème. Il n'en demeure pas moins que, s'agissant d'un poème héroï-comique, donc d'une œuvre qui ressortit au burlesque, le dialogisme se trouve au cœur de l'écriture. Or, le modèle avec lequel Lope dialogue en tout premier lieu est bien l'épopée, conçue de manière globale et pas uniquement à travers les emprunts à telle ou telle œuvre canonique. C'est l'épopée que l'auteur invite son lecteur à reconnaître d'emblée dans le titre, la proposition, la comparaison des personnages à des héros antiques ou encore l'évolution progressive du récit vers un conflit collectif.

Le lyrisme du poème lui confère une tonalité analogue à celle de nombreux sonnets des Rimas de Tomé de Burguillos, ce qui contribue à l'unité $\mathrm{du}$ recueil ${ }^{27}$. Toutefois, la jalousie est un thème central dans La Gatomaquia

27. D’après Juan Manuel Rozas et Jesús Cañas, un tiers du recueil est consacré à l'amour (Rimas humanas y divinas del Licenciado Tomé de Burguillos, p. 51). D'autres facteurs contribuent à cette unité, comme divers critiques l'ont remarqué. Felipe Pedraza écrit avec justesse : "En la epopeya burlesca alienta la finalidad consoladora y terapéutica que inspira el conjunto de las Rimas de Burguillos" (El universo poético de Lope de Vega, p. 240). On retrouve dans La Gatomaquia et le reste du recueil l'expression du désenchantement amoureux, la polémique engagée avec les poètes obscurs, la mise à distance critique par Lope de Vega de sa propre production littéraire. Insistons sur deux autres éléments d'appréciation de cette unité. Tout d'abord, la présence d'un thème cher au poète du cycle de senectute : l'absence de mécènes encourageant les grandes entreprises poétiques. Les ouvertures de la première et de la cinquième silvas sont en partie consacrées à justifier le choix d'une épopée de chats. Lope déclare dans la première que " hay hombres que se dan a gatos / por olvidos de principes ingratos" (vv. 21-22), et, dans la cinquième, qu'il ne chante pas « un hombre / de los que honraron el valor hispano" (vv. 27-28) parce que les entreprises poétiques de haut vol ne sont plus appuyées par les puissants (" como no se usa / el premio, se acobarda toda Musa", vv. 31-32). C'est le thème des tercets du sonnet 81 . Même Zapaquilda préfère aux vieux thèmes nationaux du romancero le registre de la jácara (" que, para que lo heroico y grave olviden, / hasta las gatas jácaras piden: / ;tanto el mundo decrépito delira!», III, vv. 62-64, voir également les vers 78-79). En quelque sorte, l'esprit de sérieux en poésie est présenté comme un anachronisme dans une époque décadente qui ne reconnaît pas ses grands poètes (sonnets 74 et 103. Consulter également le sonnet 4 pour une justification plus personnelle du registre choisi, et l'indispensable étude de Juan Manuel Rozas, Estudios sobre Lope de Vega, Madrid, Cátedra, 1990, en particulier les p. 118-123 pour La Gatomaquia et le cycle de senectute). Le deuxième élément que l'on souhaite souligner est la présence d'animaux choisis comme thème ou protagonistes d'un sonnet dans les compositions qui précèdent La Gatomaquia (notamment dans les poèmes 39, 49, 52, 59, 60, 63, 69, 77, 84, 94, 97, 101, 102, 119, 128, 130, 132, 143). Le lecteur ne s'étonne guère de se retrouver face à des chats après avoir vu défiler taureau, chien, singe, moineau, puce, abeille... Plusieurs de ces poèmes s'inscrivent bien sûr dans une tradition littéraire préalable. Mercedes Blanco retrouve dans certaines de ces compositions comme dans La Gatomaquia « una aguda representación antropomórfica del mundo animal». Mercedes 
alors qu'elle n'apparait que ponctuellement ailleurs ${ }^{28}$. Surtout, Lope présente l'amour comme la cause de conflits collectifs : le sentiment évoqué est celui qui perturbe l'ordre des sociétés et entraîne la guerre, ce qui est sans équivalent dans les sonnets. Cette orientation épique limite l'identification du locuteur de La Gatomaquia avec celui de Garcilaso, un poète pourtant omniprésent dans les aventures des chats. Le sonnet qui précède et introduit La Gatomaquia qualifie Tomé de Burguillos de "segundo Gatilaso", le locuteur cite ouvertement Garcilaso et prétend que ses chats connaissent les Églogues ("el gato las Églogas sabia $»^{29}$ ). De fait, Lope nous montre des chats qui miaulent et qui souffrent comme certains bergers gémissent. Mais ses chats savent également rugir, et c'est bien le modèle de l'épopée qui doit guider l'interprétation, et non celui de l'églogue. D'ailleurs, la folie de Marramaquiz, qui occupe une place médiane dans le poème (silva IV), est ouvertement comparée à celle de Roland (vv. 333-341) et non à la crise de folie d'Albanio, le berger de la deuxième églogue de Garcilaso. Étant donné les nombreuses références à ce poète, on aurait pu s'attendre à ce que la folie de Marramaquiz donne lieu à une transposition burlesque de la scène dans laquelle Salicio maittrise Albanio. Or, on ne trouve rien de tel et ce n'est pas cette facette de la folie amoureuse qui intéresse ici Lope. Il choisit d'écrire un poème héroï-comique parce que l'épopée implique une solennité, une excellence des âmes et des comportements qui se prêtent, non pas nécessairement à la parodie la plus destructrice, mais à une réécriture sur un mode mineur qui met à distance cet univers et ces comportements. Comme F. Pedraza le rappelle, Lope avait cherché, au tournant du siècle, à devenir le grand poète épique espagnol mais n'avait pas rencontré dans cette entreprise le succès escompté. Pour ce même critique, Lope n'a pas su se libérer des règles du genre épique et a écrit des épopées dans lesquelles l'abondance des matériaux finit par étouffer la trame narrative ${ }^{30}$. Au contraire, dans La Gatomaquia, Lope évite les interminables digressions qui parasitent ses épopées sérieuses ${ }^{31}$. Écrit dans le cycle de senectute par un poète qui ne

Blanco, "La agudeza en las Rimas de Tomé de Burguillos", dans Maria Grazia Profeti (sous la dir. de), "Otro Lope no ha de haber». Atti del convegno internazionale su Lope de Vega, Firenze, Alinea Editrice, 1, 2000, p. 219-240.

28. Pour le thème de la jalousie dans les Rimas de Tomé de Burguillos, consulter par exemple le sonnet 144 et, dans La Gatomaquia, IV, v. 137-146.

29. La Gatomaquia, VI, v. 168. Consulter également II, v. 55.

30. Felipe Pedraza, El universo poético de Lope de Vega, p. 69-73 ("Es sorprendente comprobar cómo los estatutos genéricos apresan y condicionan la labor del artista [...] en los poemas épicos amontona de forma antieconómica datos, referencias enciclopédicas, descripciones... y no consigue dibujar con nitidez las fuerzas argumentales", p. 72).

31. "Este formato [l'auteur fait référence aux 2801 vers du poème] implica una acción 
poursuit plus le dessein du Lope de la Dragontea, La Hermosura de Angélica ou la Jerusalén conquistada, le poème héroï-comique de Lope constitue une épopée partiellement libérée des contraintes du genre, ou plus exactement de la conception que Lope en avait. Il faut y lire l'œuvre d'un homme qui ne cherche plus à rivaliser avec d'autres pour conquérir un titre de poète épique et qui, au terme du processus de simplification mis en avant par M. Fernández Nieto, écrit une épopée dont l'efficacité poétique tient pour une large part aux libertés prises avec les règles du genre et au traitement réservé à l'univers épique ${ }^{32}$.

L'amour et la guerre se trouvent également au cœur du Poema Heroico de las necedades y locuras de Orlando el enamorado, que Quevedo composa entre 1631 et $1638^{33}$. Il reprend pour l'essentiel l'œuvre de Boiardo tout en tenant compte d'autres poèmes ${ }^{34}$. Récemment, la thèse de Pablo Lombó Mulliert a projeté un éclairage nouveau sur le travail de Quevedo. Ce poète ne crée pas uniquement à partir des poèmes italiens, il se nourrit également de la traduction du Orlando Innamorato entamée par Hernando de Acuña, et conçoit son propre poème comme une traduction parodique. Pablo Lombó estime que l'objectif de Quevedo était de réaliser la plus importante traduction parodique de l'époque baroque ${ }^{35}$.

unitaria, sin las extensas digresiones parasitarias que tanto perjudican el ritmo de sus poemas mayores ", Felipe Pedraza, ibid., p. 228. Les digressions sont nombreuses dans ce poème ( $\mathrm{La}$ Gatomaquia, p. 29-30) mais leur extension n'est effectivement pas comparable à celle des digressions présentes dans les épopées sérieuses et par ailleurs elles contribuent efficacement à la parodie.

32. Pour Marcella Trambaioli, La Gatomaquia offre également une version parodique d'une autre épopée écrite par Lope lui-même, La Hermosura de Angélica. Dans son édition de ce poème, elle déclare : " [...] el conocimiento del poema permite apreciar su utilización paródica en La Gatomaquia con claros ecos intertextuales [...] " (Lope de Vega, La Hermosura de Angélica, op. cit., p. 141, voir également p. 122).

33. Ces dates sont avancées par Pablo Lombó à partir d'un article de Fernando González Ollé, intitulé «El problema de la prioridad entre dos obras de Quevedo : el Orlando y las octavas contra Morovelli ", dans José Romera, Antonio Lorente et Ana Freire (sous la dir. de), Ex libris. Homenaje al profesor José Fradejas Lebrero, Madrid, Uned, 1, 1993, p. 285-298. Je remercie Pablo Lombó, auteur d'une thèse inédite intitulée $E l$ « Orlando » de Quevedo : tradición y traducción, qui a bien voulu me transmettre un exemplaire de son travail.

34. Voir Francisco de Quevedo, Poema heroico de las necedades y locuras de Orlando el Enamorado, Maria Malfatti (éd.), Barcelona, Sociedad Alianz de Artes Gráficas, 1964, qui permet de découvrir d'autres sources que Boiardo (pour l'importance de ce dernier consulter l'article de Giovanni Caravaggi, qui démontre que Quevedo s'inspira du texte de Boiardo plutôt que de la version qu'en proposa Berni. Giovanni Caravaggi, " Il Poema heroico de las necedades y locuras de Orlando el enamorado di Francisco de Quevedo y Villegas ", Letterature Moderne, 11, 1961, p. 325-342 et 461-474).

35. Pablo Lombó écrit, p. 89 de sa thèse inédite: «El objetivo de Quevedo era hacer su muy 
Le poème s'interrompt sur la première octave du troisième chant. Le lecteur a découvert la "cour carnavalesque ${ }^{36}$ de Charlemagne, réunie à Paris où doivent se tenir des joutes. Les paladins s'enivrent et se goinfrent quand arrive Angélique, dont la beauté prodigieuse suspend le banquet. Elle raconte alors comment un tyran a usurpé le pouvoir qui devait revenir à son frère, les poussant à fuir leur royaume pour demander l'appui de Charlemagne. Par ailleurs, son frère veut faire la preuve de sa vaillance en défiant les chevaliers qui oseraient entrer en lice avec lui pour conquérir la main d'Angélique. C'est le début de la querelle qui doit semer la zizanie à la cour de l'empereur, conformément aux plans de Galafron, roi du Cathay et père d'Angélique. Le deuxième chant raconte le duel qui oppose Argail, le frère d'Angélique, à Ferragus.

L'univers recréé par Quevedo est profondément conflictuel. Les valeurs de la chevalerie, la beauté des héros généreux, la vision profondément esthétisée des combats ainsi que l'élégance du vers héroïque transparaissent ici sous des traits certes grotesques mais qui ne suffisent pas à les faire disparaitre tout à fait du poème. Ces éléments demeurent, comme une perpétuelle réminiscence d'un monde chevaleresque que le travestissement opéré par Quevedo ne fait qu'entretenir d'une singulière façon. Naît ainsi une forme de tension entre deux univers poétiquement incompatibles, entre un chant et un contre-chant chevaleresques. La description du lieu des combats, le Padrón del Pino, fait partie des rares passages libres de cette tension (I, vv. 717-824). Elle caractérise jusqu'aux octaves qui précèdent le début du récit et qui, tout en reprenant le rituel introductif de l'épopée, avec propositio épique, appel aux muses et dédicace, nous mènent progressivement et sur un mode décalé vers l'univers des Pairs de France. Dès la propositio, Quevedo attache à ses personnages un trait physique ou moral qui les caractérise si fortement qu'ils semblent s'y réduire. Il ne s'agit pas de qualités inhérentes aux chevaliers, comme la vaillance, la prudence, la courtoisie. Roland sera le chevalier dont le comportement, dès le titre et les vers liminaires, paraît sot ("necedades") ou absurde ("Canto los disparates, las locuras, / los furores de Orlando enamorado »), Ferragus a littéralement le diable au corps

particular traducción de toda la historia de Orlando, enamorado y furioso, en un solo poema [...] ", «[...] la intención primera de Quevedo era, no ya escribir el poema más extenso de su obra en verso, sino la traducción paródica del Barroco".

36. «El Poema heroico quevediano [...] retrata una Corte del Emperador Carlo Magno que pudiéramos calificar con propiedad de carnavalesca ", écrit Carlos Mata à la page 226 d'un article consacré aux aspects carnavalesques du poème. Carlos Mata Induráin, "Aspectos satíricos y carnavalescos del Poema heroico de las necedades y locuras de Orlando el enamorado de Quevedo ", Rivista di Filologia e Letterature Ispaniche, 3, 2000, p. 225-248. 
("guerrero endemoniado »), Angélique est présentée comme une jeune fille à la vertu douteuse et qui erre comme le font les chevaliers ("niña buscona y doncellita andante "), le roi Grandonio est implicitement affublé de cornes (" de testuz arisco "), le traître Ganelon est un " basilic infâme et maudit ", "plus trompeur encore que les voiles d'une veuve » et Médore est le «cabrón desventurado". Les muses sont sommées d'inspirer des chacones et de remiser leur lyre, et Quevedo les assimile indirectement à des prostituées ${ }^{37}$. Quant au destinataire, il est "l'homme le plus maudit au monde " ${ }^{38}$, une âme damnée dont les aïeuls furent brûlés pour une raison infamante, mais qui rougiraient plus encore de leur descendant. Le banquet, avant même l'altercation qui oppose les invités, est le lieu de toutes les provocations entre le lard et le vin, les grandes coupes et les plus petites ${ }^{39}$. Le conflit porte jusqu'au langage créé par le locuteur quévédien, cet " estilo brujo » (I, v. 80) qui mêle les registres les plus bas aux plus précieux dans une confrontation permanente d'univers poétiques étrangers les uns aux autres. À propos de la comparaison épique, qui, se propageant à partir du modèle homérique, devient un des signes d'identité du genre, Daniel Madelénat écrit que "grâce à la comparaison - facteur de liaison temporelle et spatiale -, le territoire épique parachève son extension cosmique $"{ }^{40}$. Autrement dit, la comparaison est un des moyens dont dispose le poète épique pour faire sentir à l'auditeur ou au lecteur que l'affaire humaine qu'il raconte intéresse l'univers. Bien que d'une tout autre manière, le poème de Quevedo reste épique en ce sens, puisque le conflit qui divise les paladins est transposé bien au-delà de l'espace restreint du tournoi pour irradier sur l'ensemble du poème, du style et de l'univers créés par l'auteur.

La linéarité des récits dans La Moschea et La Gatomaquia marque la préférence de Villaviciosa et de Lope pour l'épopée classique lorsqu'il s’agit d'agencer les matériaux sur lesquels reposent leurs poèmes héroïcomiques. Ces auteurs écartent la technique du foisonnement d'épisodes caractéristique des romanzi, dont Lope reprend pourtant la matière et l'esprit. Par ailleurs, aucun romanzo comique n'est créé de toutes pièces en Espagne, et le travestissement semble la seule voie possible pour une réécriture sur un registre burlesque. Avançons une explication : la technique

37. Consulter les notes de Lía Schwartz et Ignacio Arellano à Francisco de Quevedo, Un Heráclito cristiano, Canta sola a Lisi y otros poemas, Barcelona, Crítica, 1998.

38. C'est ce qui apparait sous forme d'épigraphe entre le titre et l'annonce du premier chant. Quevedo précise sa pensée dans la dédicace-invective des vers 33-72.

39. Voir I, vv. 245-246, 257-260, 281-284 (je cite à partir de Francisco de Quevedo, Poesía original completa, José Manuel Blecua (éd.), Barcelona, Planeta, 1999. Le poème, auquel je ne renverrai désormais qu’en mentionnant son titre, est édité aux pages 1219-1269).

40. Daniel Madelénat, op. cit., p. 34. 
de l'entrelacement suppose une complexité de la dispositio dont le poète burlesque n'a pas à s'encombrer pour atteindre ses objectifs, qui tiennent plutôt dans la transposition comique de l'elocutio et de l'inventio des poèmes de ton élevé. C'est ce qui va m’intéresser à présent, à travers l'étude de la polyphonie.

\title{
II. Miaulements, Bourdonnements ET AUTRES VOCIFÉRATIONS HÉROÏQUES
}

Les auteurs de romanzi font souvent remonter leur récit à une tradition fixée par la chronique de l'archevêque de Reims, le fameux Turpin. Cette référence à Turpin, qui devient peu à peu une formule typique, est teintée d'ironie car elle témoigne de la vérité que le poète prête ou feint de prêter à un récit d'aventures qui relèvent parfois du merveilleux ${ }^{41}$. Cette pseudolégitimation des faits narrés transparaît également dans les trois poèmes examinés ici. Dans celui de Quevedo, c’est le principe même de la référence à Turpin qui est travesti. Le locuteur maudit, Turpin, coupable d'avoir transmis un récit sans queue ni tête, est désigné par la métaphore culinaire de la "pepitoria", la fricassée à laquelle le locuteur tente de donner forme ${ }^{42}$ :

\author{
Cuenta Turpin (jmaldiga Dios sus güesos, \\ pues tan escura nos dejó la historia, \\ que es menester buscar con dos sabuesos \\ una cabeza en tanta pepitoria!), \\ digo que cuenta ovillos de sucesos, \\ con que nos dio confusa la memoria \\ que, en las ochas que veis, desarrebujo, \\ con verso suelto y con estilo brujo. (I, vv. 73-80)
}

41. Sergio Zatti a brillamment montré l'importance de Turpin dans le romanzo, en particulier dans l'Orlando Furioso. Il examine, entre autres, comment l'autorité de Turpin est invoquée pour justifier la sélection et l'organisation des matériaux constitutifs du récit, ainsi que "l'insistenza ironica di Ariosto sulla veridicità delle parti più inverosimili di un poema già favoloso nel suo complesso [...]", et la "scherzosa filologia » de l'auteur. Sergio Zatti, Il Furioso fra epos e romanzo, chapitre VII, "Il ruolo di Turpino : poesia e verità nel Furioso ", p. 173212, nos citations aux p. 195 et 193. Lope renvoie également à Turpin avec ironie dans $\mathrm{La}$ Hermosura de Angélica (consulter sur ce point l'introduction de M. Trambaioli à l'édition citée, p. 116-119).

42. Sur le sens métalittéraire de la pepitoria, lire Christel Sola, "Destas novelas que te ofrezco en ningún modo podrás hacer pepitoria" : aproximación a la práctica cervantina de la colección de novelas ", Criticón, 97-98, 2006, p. 89-105. 
Villaviciosa mentionne lui-aussi Turpin, qui serait à l'origine de l'histoire narrée par Folengo. L'auteur espagnol joue avec cette pseudo-autorité dédoublée sur laquelle reposerait la vérité de son récit ${ }^{43}$. S'agissant d'un combat de mouches et de fourmis, la question de la vérité de la fable est oiseuse et la poser ne fait que participer au comique de l'œuvre. C'est un ressort que Villaviciosa exploite dans la suite du poème en anticipant les réserves du lecteur " discreto » et ses doutes quant à la vérité de la fable. A ces réserves le locuteur oppose la caution des autorités littéraires ou bien une démonstration sophistique visant à prouver que ce qui est avancé est fondé. Prenons un exemple. Dans le premier chant, le locuteur raconte que les mouches, lors de la fondation de la cité, remontèrent d'un trou béant la carcasse d'une tête de vache. Un lecteur à l'affût de la moindre invraisemblance pourrait s'étonner que les personnages aient si facilement reconnu une vache plutôt qu'un bœuf. Voici la réponse du locuteur :
Mas ya el discreto su argumento saca
de grande fuerza y de profundo fondo,
pues no se pudo ver si era de vaca
o cabeza de buey el hueso mondo.
Pero su fuerza el silogismo aplaca
con sola esta razón que le respondo:
que a mi no me está bien en traducciones
contradecir antiguas tradiciones.

Con esto satisfago al que es discreto,

y volviendo a la historia verdadera,

de la sima sacaron en efeto

esta terrible y grande calavera. (I, vv. 353-364)

D'autres exemples pourraient illustrer cet usage de la rhétorique comme d'un art qui permet de couper court aux réserves du lecteur qui douterait de la vérité de l'histoire, ou plus généralement des explications apportées par le locuteur ${ }^{44}$. Il s'agit toujours de "satisfacer al discreto", satisfaire le lecteur qui se croit malin, le moucher, si l'on peut dire. L'étymologie burlesque qu'un personnage attribue au substantif retórica, qui viendrait de reto (X, vv. 361368), est symptomatique de la relation établie entre le locuteur et le lecteur. Dans ces passages, le locuteur veut briller, rivaliser d'adresse avec le lecteur, faire preuve d'un panache qui n'est pas sans rapport avec l'ethos chevaleresque de ses personnages.

43. Consulter sur ce point l'introduction de Ángel Luis Luján à La Moschea, p. 75-79.

44. Voir I, vv. 233-240, II, vv. 57-64 et 241-248 (ici, c’est Sanguileón qui s'exprime), X, vv. 97-120. 
Lope lui aussi devance les réserves du lecteur critique. À celui qui douterait que les singes puissent aimer, il rétorque qu'il n'a qu'à vérifier ses dires en Afrique ; à tel autre qui remettrait en question l'existence de minuscules chevaux, il l'envoie au pays des Pygmées, tout en précisant que le lecteur peut bien croire ce qui lui chante et qu'il n'y a pas de poésie sans mensonge ${ }^{45}$. Cette insolence du locuteur burlesque constitue la réponse de nos auteurs à la question de la vraisemblance dans la fable épique, qui apparait comme un faux problème lorsque les personnages sont des mouches ou des chats.

La voix du locuteur burlesque n'est pas la seule qui résonne dans nos trois poèmes. C'est dans La Gatomaquia que la rencontre du barde et du bouffon donne lieu au chant polyphonique ${ }^{46}$ le plus harmonieux. Lope

45. La Gatomaquia, IV, vv. 41-66, VII, vv. 77-144. Comparer avec Lope de Vega, La Hermosura de Angélica, op. cit., VII, vv. 197-200 et note de M. Trambaioli. La figure du locuteur dans les Rimas humanas y divinas del Licenciado Tomé de Burguillos a été examinée avec beaucoup de finesse par Javier San José Lera. L'auteur s'intéresse notamment à la modernité de Lope dans cette œuvre en mettant en avant une conception de l'écriture littéraire comparable à celle de Cervantes. Javier San José Lera, "Tomé de Burguillos o el triunfo del Quijote. Una lectura de las Rimas humanas y divinas del licenciado Tomé de Burguillos de Lope de Vega ", Criticón, 100, 2007, p. 167-199. Consulter également Felipe Pedraza, El universo poético de Lope de Vega, p. 238-239.

46. J'emprunte ici un concept bien connu de la théorie du roman de Bakhtine, dont l'essentiel est exposé dans le volume réunissant des essais de différentes époques, Mikhail Bakhtine, Esthétique et théorie du roman, Paris, Gallimard, 2003 (1 ìre éd. 1978). Tzvetan Todorov analyse ces écrits dans Mikhaïl Bakhtine. Le principe dialogique, Paris, Seuil, 1981. Rappelons que pour Bakhtine tout énoncé intégré à un texte littéraire traduit un univers et un point de vue sociolinguistiques. Par ailleurs, tout énoncé entretient un rapport dialogique avec d'autres énoncés avec lesquels il entre en corrélation de manière implicite. Ce dialogisme pourra prendre une forme in absentia, "c'est-à-dire entre le style homogène de l'œuvre et les autres styles dominants de l'époque " ou une forme in praesentia, "à l'intérieur de l'œuvre " (Tzvetan Todorov, op. cit., p. 119). La réception critique d'un texte littéraire suppose donc la perception des « langages étrangers " présents -ne serait-ce qu'implicitement- dans le texte. Le mélange de ces langages donne lieu à la polyphonie. Certes, Bakhtine développait une théorie du roman. Mais l'on voit bien que ses concepts sont opérationnels pour la poésie burlesque. Le locuteur burlesque est celui qui confère une légitimité poétique à ce qu'un locuteur plus sérieux écarte du domaine poétique : la laideur physique ridicule, la maladie honteuse, les plaisirs sensuels coupables, mais aussi toutes sortes de référents prosaïques chantés dans les capitoli italiens : la carotte, le pot de chambre, etc. Dans nos poèmes, cette voix du locuteur burlesque s'exprime dans un contexte épique. La voix du locuteur épique, ou celle du locuteur de la poésie chevaleresque, se laissent également entendre et entretiennent avec celle du locuteur burlesque une relation dialogique. Plus généralement, le concept de dialogisme in absentia est le plus stimulant pour l'étude du burlesque dans la mesure où il impose de concevoir le burlesque comme un registre nécessairement corrélé à un autre registre du champ poétique. Sur la polyphonie, consulter également Federico Bravo, "Postures et impostures énonciatives. Notes sur le discours polyphonique ", 
accorde une telle place à l'amour que les voix les plus graves du poème demeurent toujours dans un registre tempéré. Il privilégie la "vaghezza" sur la " gravità " préconisée par le Tasse pour le poème épique ${ }^{47}$. Par ailleurs, la voix du bouffon ne tombe jamais vraiment dans un comique outrancier, dans le grotesque le plus cru, contrairement à ce qui se produit sous la plume de Quevedo. Il n'y a donc pas de fausses notes dans cette polyphonie toute en mesure, parfaitement adaptée au plaisant badinage auquel se livre Lope. Contrairement aux poèmes de Quevedo et Villaviciosa, La Gatomaquia illustre l'esthétique du "tissu moiré » théorisée par Tassoni dans les paratextes de sa Secchia Rapita. Pour cet auteur, le mélange des registres ne doit reposer ni sur la disconvenance ni sur la simple alternance :

Cette œuvre $[\ldots]$ est tissée de telle sorte qu'il ne lui manque aucun des éléments qui, tant pour la matière que pour le style, sont requis dans le parfait poème grave et burlesque. Et ce n'est pas, comme d'aucuns l'affirment, une étoffe à rayures, ou, comme le veulent d'autres, la livrée d'un Suisse, mais plutôt un tissu moiré, dans lequel les deux couleurs du grave et du burlesque resplendissent admirablement. Et, sur ce point, certains se sont trompés, qui crurent faire la même chose en chantant une matière totalement burlesque avec des vers graves, ou une matière totalement grave avec des vers burlesques ${ }^{48}$.

Bulletin Hispanique, 95-1, 1993, p. 59-97 ; Geneviève Champeau, "Ronda del Guinardó de Juan Marsé: un roman polyphonique ", Bulletin Hispanique, 95-1, 1993, p. 203-223 ; Jesús G. Maestro, "La expresión dialógica en los sonetos de las Rimas de Tomé de Burguillos ", dans María Cruz García de Enterría et Alicia Cordón Mesa (sous la dir. de), Actas del IV congreso internacional de la AISO, Alcalá de Henares, Universidad de Alcalá, 1, 1998, p. 711-722; Mirna Velcic-Canivez, «La polyphonie : Bakhtine et Ducrot ", Poétique, 131, 2002, p. 369384.

47. "Lo stile eroico adunque non è lontano dalla gravità del tragico né dalla vaghezza del lirico, ma avanza l'uno e l'altro nello splendore d'una meravigliosa maestà ", Torquato Tasso, op. cit., p. 198.

48. Traduction personnelle du texte de Tassoni, que l'on pourra consulter dans Alessandro Tassoni, La Secchia Rapita, Francesco Luigi Mannucci (éd.), Torino, Unione Tipografico, 1948, p. 47-48. Le style de Tassoni a été commenté par R. Rinaldi, "Con cambio secco": geometrie del Tassoni ", dans Giorgio Barberi Squarotti (sous la dir. de), Teoria e storia dei generi letterari. Il poema eroicomico, Torino, Tirrenia Stampatori, 2001, p. 66-74. Consulter également, dans le même volume, l'article de L. Montella, «Il poema eroicomico e La Secchia Rapita di Alessandro Tassoni (I canto) », p. 75-84. Dans son article sur le trait d'esprit dans les Rimas humanas y divinas de Tomé de Burguillos, Mercedes Blanco commente plusieurs sonnets de Lope à la lumière du texte de Tassoni, et évoque la « unidad dialéctica y paradójica entre veras y burlas que reclamaba Tassoni para un poema perfecto". 
Comment atteindre cet harmonieux mélange ? Lope y parvient en superposant deux univers différents, celui des chats et celui des preux chevaliers, sans que l'un efface l'autre. Observons les vers suivants, dans lesquels Marramaquiz reproche à Zapaquilda de l'avoir abandonné :

\author{
Si no te he dado telas y damascos \\ es porque tú no quieres vestir galas \\ sobre las naturales martingalas, \\ por no ofender, ingrata a tu belleza, \\ las naguas que te dio naturaleza; \\ pero en lo que es regalos, ¿quién ha sido \\ más cuidadoso, como tú lo sabes, \\ en cuanto en las cocinas, atrevido, \\ pude garrafiñar de peces y aves? \\ ¿Qué pastel no te truje, qué salchicha? \\ ¡Oh terrible desdicha! \\ Pues no soy yo tan feo; \\ que ayer me vi, mas no como me veo, \\ en un caldero de agua que de un pozo \\ sacó, para regar mi casa, un mozo; \\ $y$ dije: ¿Esto desprecia Zapaquilda? \\ ¡Oh celos!, ;oh piedad!, ;oh Amor!, ;reñilda! (I, vv. 342-358)
}

Les derniers vers, alors que Marramaquiz observe le reflet de son visage sur la surface de l'eau, reproduisent une situation typique de la littérature pastorale ${ }^{49}$. Dans ce passage, le discours entre progressivement dans une forme de pathos souligné d'abord par les questions oratoires puis par les tournures exclamatives. C'est le ton de la complainte, parfaitement sérieuse quant à ses motifs et à ses intentions. En revanche, les présents offerts par Marramaquiz, des saucisses, des pâtés, des poissons et autres volailles renvoient à un univers étranger aux amants délaissés par une dame ingrate, un univers dont seule la voix du locuteur burlesque peut rendre compte : celui de la cuisine. De même, dans les premiers vers, Marramaquiz cite d'abord les riches atours qu'un galant offre à sa promise, pour évoquer ensuite "las naturales martingalas", "las naguas que te dio naturaleza ", ce qui désigne sous forme métaphorique le pelage de Zapaquilda. Sur le plan formel, on passe d'un univers à l'autre. Néanmoins, c'est bien l'esthétique du " tissu moiré » et non celle de "l'étoffe à rayures " qu'illustre ce texte. En effet, Lope évite que ces transitions soient marquées par une modification radicale

49. La note de Celina Sabor renvoie notamment à Théocrite, Virgile et Garcilaso. 
du registre choisi. Bien sûr, le poème n'est pas dénué de quelques envolées épiques. Mais, globalement, il n'y a pas d'alternance véritable d'un registre élevé et d'un registre bas. Aussi, le plan mimétique, celui des chats, et le plan sémiotique, celui des héros et de l'amour courtois, ne sont presque jamais séparables ${ }^{50}$. Sur le plan sémiotique, ce discours de Marramaquiz renvoie à la complainte de l'amant courtois se plaignant de l'infidélité féminine, et, certes, l'introduction de saucisses dans cet univers doit paraître incongrue. Cette incongruité constitue un ressort du comique. Mais sur un plan mimétique, il est parfaitement cohérent que les chats ne portent pas de vêtements et hantent les cuisines. Le plaisir du texte de Lope, ce qui en fait la saveur si particulière, c'est précisément qu'il semble si souvent cohérent et incongru à la fois, selon le plan envisagé. Dans un autre passage, Marramaquiz, à cheval sur une guenon, fait le beau sous les fenêtres de sa bien-aimée ${ }^{51}$. Une telle attitude est incongrue sur le plan mimétique, mais tout à fait concevable sur le plan sémiotique, ce passage devant être interprété à la lumière de la poésie chevaleresque dont il s'inspire. Examinons à présent la scène de l'enlèvement de Zapaquilda par Marramaquiz :

\author{
En fin, llegando donde ya tenía \\ Zapaquilda la vida por segura, \\ le dijo: "Tente, ¿dónde vas, perjura?" \\ Ella, temblando, respondió turbada: \\ "Huyendo el filo de tu injusta espada \\ que se quiere vengar de mi inocencia \\ con tan fiera insolencia, \\ quitándome mi esposo; \\ pero yo me sabré quitar la vida, \\ Polifemo de gatos." \\ "Ojos hermosos siempre y siempre ingratos \\ -le respondió furioso-, \\ ¿desa manera habláis en mi presencia? \\ ¡Oh gata la más loca y atrevida! \\ Yo solo soy tu esposo, fementida ;
}

50. Je reprends la terminologie employée par Michael Riffaterre, op. cit. Essayons d'expliquer très brièvement ces termes. Le plan mimétique correspond à ce que le texte désigne littéralement en entretenant une illusion de référentialité. Mais le texte littéraire est bien plus que l'ensemble des mots qui le composent ; son interprétation réside également dans la perception de textes antérieurs, de citations, de clichés, de conventions littéraires, de thèmes ou de paradigmes auxquels ce texte renvoie, et qui constituent le plan sémiotique. L'interprétation naît de la confrontation de ces plans mimétique et sémiotique.

51. La Gatomaquia, I, vv. 143 et suivants. 


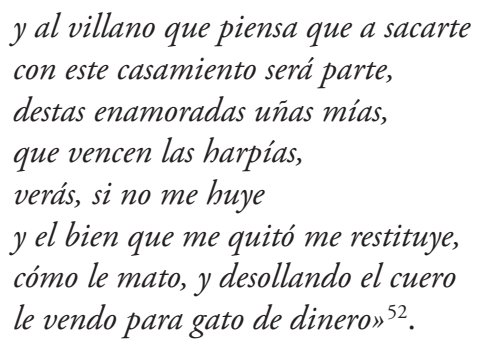

Sur le plan sémiotique, le registre choisi renvoie à l'univers de la poésie amoureuse et à certaines scènes de la comedia, un univers qui n'a pas grand-chose à voir avec celui qui correspond au plan mimétique, celui des chats dont le locuteur nous conte les aventures. Or, ce plan mimétique ne disparaît jamais totalement dans La Gatomaquia, tant les personnages, tout en singeant les hommes, agissent en chats. Rien que dans cette vingtaine de vers, cinq mots nous rappellent à qui nous avons affaire ("Polifemo de gatos", " ¡Oh gata la más loca y atrevida!", " uñas mías ", " desollando el cuero", "gato de dinero").

Un dernier extrait illustrera mon propos. Cette fois, l'esthétique du " tissu moiré " transparaît dans la description de situations où le ridicule et l'élégance se confondent. Lope décrit des chats à fière allure mais qui, en même temps, prêtent à rire. Dans le passage qui suit, il raconte le voyage entrepris par les chats qu'attire la beauté de Zapaquilda :

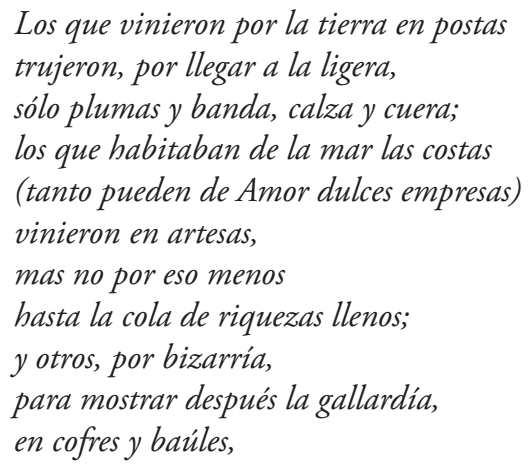

52. La Gatomaquia, V, vv. 344-366. Les poètes burlesques tirent souvent profit de la richesse sémantique de gato, qui désigne le chat, le voleur, ou encore la bourse confectionnée à partir de la peau du chat. Par ailleurs, Roland Béhar me signale que ce passage pourrait constituer un lointain écho de la deuxième églogue de Garcilaso. Dans cette composition, Camila refuse de se livrer à Albanio ("antes verás mi muerte / que tú me cobres ni a tus manos hayas", vv. 863-864) qui lui reproche de ne pas être fidèle à sa promesse (" iAh, ninfa desleal!, ¿y desa suerte / se guarda el juramento que me diste? ", vv. 865-866). 


\author{
sulcando las azules \\ montañas de Anfitrite, \\ $y$ alguno, que a disfraces se remite \\ por no ser conocido, \\ en una caja de orinal metido. (I, vv. 221-236)
}

Richement parés de leurs plus beaux atours, ces preux félins affrontent les montagnes azurées d'Amphitrite dans des malles ou des pots de chambre. Lope, à travers la voix du locuteur épique, prête à ses personnages des motivations et des attitudes dignes de héros ("por bizarría", "para mostrar después la gallardía") tout en introduisant des détails que seul le locuteur burlesque peut mentionner ("vinieron en artesas", "en una caja de orinal metido»). L'arrogance des chats, qui renvoie par analogie au panache des héros chevaleresques ou épiques, transparaît ainsi dans des situations décrites avec une pointe d'ironie. Cette mise en scène de personnages risibles et héroïques à la fois maintient dans l'énonciation une ambiguïté qui contribue au mélange des tonalités propre à l'esthétique du " tissu moiré ».

La polyphonie dans La Gatomaquia prend une forme que l'on doit considérer exemplaire parce qu'il ne s'agit pas que de l'alternance de plusieurs voix, mais de la découverte d'une voix médiane qui rend possible une superposition presque continue des plans mimétique et sémiotique. La prouesse de Lope est d'avoir su maintenir ce ton spécifique et original. Il était très opportun de choisir une forme métrique qui contribue à la légèreté et au lyrisme du poème, la silva. Comme cela a été signalés3, la silva est plus souple que le mètre le plus couramment utilisé jusqu’alors dans les épopées sérieuses comme dans les épopées parodiques, la octava real, strophe de huit hendécasyllabes rimant sur le schéma ABABABCC. Le Tasse considérait cette combinaison comme la mieux adaptée à la majesté et à la gravité inhérentes à l'épopée (" [...] ne la stanza d'otto versi d'undici sillabe è maggiore uniformità e maggior gravità e maggior costanza e stabilità [...]"). Daniel Madelénat constate d'ailleurs fort justement que «la régularité du mètre épique évoque les masses humaines rangées et rythmées " ${ }^{54}$. C'est le mètre choisi par Lope dans La Dragontea, La hermosura de Angélica ou la Jerusalén conquistada. En

53. José María Balcells, dans l'article déjà cité, a très bien commenté l'importance du choix de la silva. Consulter également l'introduction de C. Sabor de Cortázar, p. 32-33 ( La silva [...] combina heptasílabos y endecasílabos, sin limitación de versos. La usada por Lope en este poema es la silva de consonantes, en la cual los pareados se suceden, excepto algún verso libre o algún caso de rima cruzada. La elegancia, el refinamiento amable, el tono conversacional discreto [...] necesitaban un vehiculo grácil, sin rigideces técnicas [...]"). Pour l'octave dans l'épopée, Frank Pierce, «La poesía épica española del Siglo de oro », Edad de Oro, 4, 1985, p. 87-115.

54. Torquato Tasso, op. cit., p. 252; Daniel Madelénat, op. cit., p. 66. 
revanche, il retient un mètre plus souple lorsqu'il crée son poème épique hagiographique, Isidro, rédigé en quintillas ${ }^{55}$. Pour son épopée parodique, Lope préfere la silva, qui offre une grande liberté dans l'enchaînement des rimes mais aussi des vers de sept et onze syllabes. Surtout, elle introduit une irrégularité rythmique propre à refléter la variation des tonalités et des accents polyphoniques de La Gatomaquia.

Villaviciosa adopte la régularité de l'octave, tout comme Quevedo la reprend de Boiardo. Il s'agit d'un mètre parfaitement adapté à la solennité caractéristique du locuteur de La Moschea, dont le ton reste souvent élevé. La critique a insisté sur les implications de cette emphase qui fait que le lecteur finit par oublier parfois que les héros sont des mouches et des fourmis ${ }^{56}$. Villaviciosa sait recréer un décor épique, décrire les troupes en ordre de marche, les bannières qui flottent au vent, le fracas des armes, l'ardeur des soldats qui s'apprêtent au combat. On appréciera, par exemple, l'élégante description de la flotte des mouches, au chant IV :

Con setecientas máquinas disformes
rompe las ondas la vistosa armada
que lleva con los ánimos conformes
el bravo orgullo de la gente alada.
Infinitas catervas multiformes
sulcan en ella la región salada,
admirando las ninfas que los miran
y medrosas de verlos se retiran.
Pasa la turba indómita contenta
y el grito del placer al cielo toca,
y el viento alegre el pecho les alienta,
que a la dura venganza se provoca.
No temen del camino la tormenta,
escollo o calma o peligrosa roca,
que con gritos de gozo el aire hienden
y el mar hinchado con el remo ofenden.

55. On trouvera une bonne introduction à ces poèmes épiques dans Felipe Pedraza, $E l$ universo poético de Lope de Vega, p. 69-88.

56. Ángel Luis Luján Atienza écrit: « [...] el mantenimiento del estilo elevado es tan coherente y está tan sostenido que si olvidamos por un momento que se trata de una lucha entre bichos podíamos estar leyendo perfectamente un digno ejemplo de enfrentamiento épico ", La Moschea, p. 35. 


\begin{abstract}
Hacen las muchas olas resistencia
a los navios de que el mar se viste, reprimiendo con furia la violencia con que la fuerte máquina le embiste. Hace el viento a las olas competencia, y como el mar sus soplos no resiste, rompe soberbio el cristalino paso con leves cursos el ligero vaso.
\end{abstract}

Con orden grande y singular concierto va caminando la vistosa flota $[\text {... }]^{57}$

Le comique de La Moschea ne tient pas qu'à la nature des personnages. Certains glissements vers le " bas corporel " tempèrent les accents épiques du poète ${ }^{58}$. Mais ces passages ne font que nuancer la retenue caractéristique de Villaviciosa. Il tait, par exemple, le nom de la sœur de Sanguileón, que Folengo avait baptisée Merdola ${ }^{59}$. A la relative facilité de ce comique qui repose sur les effets de grotesque Villaviciosa préfère un humour qui consiste à créer un décalage en rappelant à qui le lecteur a véritablement affaire. C'est ainsi, par exemple, qu'il décrit avec une certaine emphase la monture de l'un des personnages, sa force et la couleur de sa robe, pour conclure en précisant que cette monture n'est qu'un grillon :
Era el caballo de admirable brio,
de la especie de aquellos que sustenta
la primavera, y que en el seco estio
el cielo tiene de sus vidas cuenta.
En fin, era de aquellos que el rocio
con su frescura engorda y alimenta,
de fuertes miembros y color morcillos,
casta maravillosa, el nombre grillos ${ }^{60}$.

57. La Moschea, IV, vv. 97-122. Parmi d'autres exemples possibles, citons également le combat entre Sicaborón et les puces du chant VI, ainsi que IX, vv. 385-416 et X, vv. 185208.

58. J'emploie « bas corporel » et " grotesque » dans le sens que leur donne Mikhail Bakhtine dans L'ouvre de François Rabelais et la culture populaire au Moyen Âge et sous la Renaissance, Paris, Gallimard, 2001 (1 ère éd. 1970). Les vers 337-352 du chant III sont de bons exemples de la présence de ce « bas corporel ». Dans le chant V, la description des vents n’est pas dénuée d'allusions scatologiques.

59. Je m’appuie sur la note de Ángel Luis Luján, p. 188.

60. La Moschea, III, vv. 209-216. L’octave qui précède illustre également mon propos. 
La superposition des plans mimétique et sémiotique, envisagée à propos du poème de Lope, ne caractérise La Moschea que dans une moindre mesure. Toutefois, Villaviciosa tire profit des caractéristiques de ses personnages en rappelant quelles sont les armes véritables de ses guerriers. Ainsi, la description de soldats singulièrement belliqueux et capables de forcer les accès les plus imprenables est d'autant plus piquante que leurs armes sont dignes de l'épopée tout en appartenant en propre à ces guerriers, puisqu'il s'agit de puces :
Es gente belicosa, que atormenta sin humanos respetos $y$ sin duelo, que tercia al hombro la soberbia pica y emponzoña la parte adonde pica.
Es turba astuta, en los ardides sabia, que suele entrarse por lo más estrecho a dar mal rato y a morder con rabia, con que nos muestra bien la de su pecho. (VII, vv. 285-292).

L'humour de ce passage tient également à un procédé commun aux locuteurs de Villaviciosa et Lope : évoquer l'humanité des personnages (" humanos respetos ") ${ }^{61}$. Les félins de Lope oublient parfois qui ils sont et dans quel univers ils évoluent, quand ce n'est pas le locuteur lui-même qui feint d'oublier qui sont réellement ses personnages. Micifuf ironise sur la prouesse de Marramaquiz, vainqueur de Garraf, en précisant que ce dernier n'était qu'un chat ; il refuse d'empoisonner son ennemi, considérant que cette mort ne vaut que pour les princes et les rois, mais pas pour ceux à qui s'appliquent les lois humaines ("Esa es muerte de principes y reyes / con quien no valen las humanas leyes "). Le locuteur, évoquant le triste sort d'une souris tombée entre les griffes de Marramaquiz, rappelle que rien n'est jamais acquis aux êtres humains ${ }^{62}$. Ce procédé ironique passe inaperçu si le poète ne fait pas coexister dans le texte les deux univers de référence. Un simple

61. Comparer avec IV, vv. 289-290 ("Lleva el fiero inhumano a la milicia / una soberbia multitud de abejas »); VII, v. 456 ("Que no hay quien ser humana mosca piense »); X, vv. 449451 ("Causó en el campo del hormiga asombro / porque ignoraban que animal humano / pudiera echar tan grave carga al hombro"). Voir également, chant V, vv. 382, 482 et 529, les syntagmes "miserables gentes", "gente misera ", "pobre gente».

62. "no hay seguridad en cosa humana" (IV, v. 287), les autres passages se trouvent dans III, vv. 214-215 et 231-232. Felipe Pedraza, dans El universo poético de Lope de Vega, p. 230, indique: "Como recordó Rodríguez Marín, abundan en el poema los intencionados lapsus linguae en los que Lope "olvida [...] que son gatos los que hablan en su poema"». 
syntagme, comme " humana mosca " ou "animal humano", peut suffire à faire coexister ces deux univers. Villaviciosa ne construit pas son poème sur la superposition quasi-permanente des plans sémiotique et mimétique. C'est pour cela que l'esthétique de la Moschea ne préfigure pas celle du " tissu moiré » de Tassoni. C'est une polyphonie dans laquelle la voix épique domine et prétend toujours narrer des faits extraordinaires, et en cela dignes de l'épopée.

La polyphonie dans le poème de Quevedo ne laisse qu'une place limitée à la voix du locuteur épique. Rares sont les fragments qui interrompent l'incessant tumulte des paladins. Il arrive parfois, néanmoins, que le locuteur décrive une scène dont la sérénité détonne quelque peu. Il en va ainsi dans ce beau passage qui évoque le paysage traversé par Astolphe et le scintillement de la lune à la surface de l'eau :

\section{Cansadas de caminos retorcidos del río sonoroso las corrientes, en pacificos lagos extendidos descansan las jornadas de sus fuentes; coronados están, como ceñidos, de sauces y de hayas eminentes; tienen por baño y por espejo el lago la luna errante, el sol errante y vago.}

Nada enjuta la luz del firmamento; el ocioso cristal de la laguna arde en trémulo y vario movimiento, y en el fondo se ve más oportuna; riza espumoso el lago fresco viento, que en los golfos pudiera ser fortuna; tiemblan las ondas, $y$, en doblez de plata, la luna ya se encoge y se dilata. (II, vv. 129-144)

Ces vers ne doivent pas faire illusion, ils ne sont pas représentatifs de la tonalité du Poema heroico de las necedades y locuras de Orlando el enamorado. Dans cet extrait, le locuteur décrit un univers où tout n'est qu'ordre et beauté, un univers étranger à celui dans lequel évoluent les personnages. Du point de vue de l'énonciation, Quevedo adopte ici un " langage étranger " ${ }^{63}$, le locuteur semblant soudain appartenir à un univers sociolinguistique qui n'est plus l'univers de référence du travestissement burlesque, qui correspondrait

63. Pour le concept de "langages étrangers ", consulter Mikhail Bakhtine, Esthétique et théorie du roman, Paris, Gallimard, 2003. 
plutôt à la " cour carnavalesque » de Charlemagne. La strophe suivante, en revanche, illustre la forme prise par la polyphonie dans le poème de Quevedo :

\author{
Llegóse el plazo que a la justa habia \\ señalado el gran Carlos y a su gente; \\ el Indo le lavó la cara al día, \\ y en perlas nevó el oro de su frente; \\ con más joyas el cielo se reía; \\ ardió en piropos el balcón de Oriente: \\ por verle, las estrellas, embobadas, \\ detuvieron al sueño las jornadas. (III, vv. 1-8)
}

La description de l'aurore subit un processus de méiose par lequel le jour, puisqu'il se lève, doit se débarbouiller le visage ${ }^{64}$. La traditionnelle évocation du balcon d'où émerge le jour, bien documentée par María Rosa Lida de Malkiel $^{65}$, se trouve en quelque sorte contaminée par une scène qui, elle, ne doit rien à la mythologie, celle de l'amant faisant sa cour sous les fenêtres de sa promise ${ }^{66}$. La beauté de l'astre solaire stupéfie les étoiles, qui, tout ébaubies, tardent à lui laisser la place. Dans le poème de Quevedo, le travestissement ne repose pas sur l'inversion systématique des motifs mais sur une transformation ludique d'expressions, d'images, de situations fixées et figées par l'usage. Cette transformation crée un langage singulier dans lequel perce encore la voix de l'idéalisme et de l'épopée. Mais, dans ce jeu polyphonique, elle n'est plus qu'un lointain écho qui doit permettre

64. "Lavar la cara. Además del sentido recto, por semejanza se toma por limpiar, asear, y en cierta manera adornar y renovar alguna cosa: y asi se dice de una casa, de un coche, de una pintura y de otras cosas se le lavó la cara y se aseó. [...] Lavarle la cara a alguno. [...] Adularle, lisonjearle para tener entrada con él». Diccionario de Autoridades, "cara ". Le premier sens intervient certainement "además del sentido recto » dans le processus de méiose.

65. María Rosa Lida de Malkiel, La tradición clásica en España, Barcelona, Ariel, 1975, p. 119-164. Aux pages 162-164, l'auteur examine la parodie du motif chez Cervantes, et notamment l'évocation du balcon.

66. Au dix-septième siècle, "piropo " désigne une pierre précieuse. Dans les vers qui nous occupent, ce sens entre en corrélation avec "perlas", "oro ", "joyas». Toutefois, Corominas indique que l'évolution progressive vers le sens actuel de " compliment amoureux » est déjà entamée à l'époque (Joan Corominas, Diccionario crítico etimológico de la lengua castellana, Berne, Editorial Francke, 1954). Ce passage de Quevedo me semble l'illustrer. "Arder " signifie également " amar con vehemencia" (Aut.). Le vers " ardió en piropos el balcón de Oriente " désigne le rayonnement de l'astre solaire apparaissant sur le balcon mais aussi les réactions ardentes provoquées par cette sortie. Le comportement prêté ensuite aux étoiles va dans ce sens. 
au lecteur de deviner ce qu'un locuteur plus sérieux aurait pu dire, et de percevoir ainsi le contraste.

Le poète choisit son registre à l'aune de la gravité qu'il prête ou feint de prêter aux faits narrés ${ }^{67}$. Lope assume la légèreté de son récit jusqu'à ses ultimes conséquences : il écrit une épopée énoncée sur un mode mineur, une épopée romanesque et comique à l'héroïsme teinté d'ironie. Villaviciosa lui aussi assume jusqu'au bout son projet littéraire, qui consiste à rédiger une épopée de mouches et de fourmis sans jamais quitter totalement le terrain épique $^{68}$. En quelque sorte, il feint de prendre ses mouches et ses fourmis au sérieux là où Lope s'amuse avec ses chats. Il s'agit de deux épopées animalières également ambitieuses mais qui illustrent des projets littéraires différents, et des conceptions du poème héroï-comique distinctes. Le poème de Quevedo se singularise face aux deux autres puisque son travestissement implique une polyphonie dans laquelle la voix du locuteur épique sonne faux, comme si, face au contre-chant chevaleresque, le chant lui-même ne pouvait qu'être dissonant. Pourtant, on va le voir à présent, les personnages les plus importants des trois poèmes adhèrent tous à l'ethos des héros.

\section{L'ETHOS DES HÉROS}

La poésie burlesque abonde en personnages ridicules ${ }^{69}$. La beauté, la chasteté, la générosité disparaissent souvent au profit de leurs doubles négatifs, la laideur, la lubricité, la pingrerie. Le poète renvoie alors implicitement à un univers étranger à celui qu'il prétend recréer, univers que le "lecteur modèle ${ }^{70}$ doit savoir retrouver. On s'attend donc à ce que les poèmes burlesques qui s'inspirent directement du genre épique soient peuplés de personnages qui vont à rebours de l'ethos et de la rhétorique des héros, à

67. "The language must emulate the weight of the story with its own austere solemnity" écrit Thomas Greene dans "The Norms of Epic ", Comparative Literature, 13, 3, 1961, p. 193207.

68. Ángel Luis Luján a approfondi l'interprétation du poème de Villaviciosa en faisant du paradoxe une figure centrale de l'énonciation. "En Villaviciosa la burla es un mecanismo paradójico que implica a la vez distancia y acercamiento. Los limites entre lo serio y lo burlesco quedan anulados [...] Villaviciosa [...] invita al lector a esta doble lectura lúdica y comprometida». La Moschea, p. 96.

69. Sur ces personnages, on consultera par exemple Ignacio Arellano, Poesía satírico burlesca de Quevedo. Estudio y anotación filológica de los sonetos, Madrid, Frankfurt-am-Main, Iberoamericana, Vervuert, 2003 (en particulier la première partie, El retablo y sus figuras).

70. Sur le lecteur modèle, voir Umberto Eco, Lector in fabula. Le rôle du lecteur, Paris, Grasset, 1985. 
l'image de ceux du romance quévédien Burla el poeta de Medoro, y Medoro de los pares. Dans ce poème d'inspiration ariostéenne, Angélique accueille sans manières les bons payeurs, et ne fait aucun cas des hauts faits chevaleresques. Médore l'a compris et se moque ouvertement des exploits des Roland et autres Rodomont :

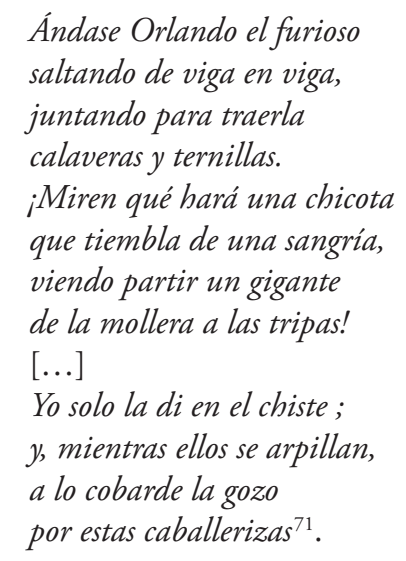

Médore prend ici le contre-pied de l'ethos chevaleresque en raillant les efforts héroïques de ses rivaux. Dans d'autres poèmes burlesques, le héros épique devient un soldat fanfaron. Góngora nous en a laissé un bel exemple avec son "alférez de mentira " qui, parce qu'il était trop enrhumé ou n'avait rien à se mettre pour sortir, ne put s'illustrer ni à la bataille d'Ypres ni à celle $\mathrm{d}^{\prime}$ Anvers ${ }^{72}$. On pourrait encore citer un capitaine de Castillejo qui, sans être totalement un anti-héros, tient un discours incompatible avec l'audace propre au personnage épique. Ce capitaine ne se contente pas d'inviter ses soldats à prendre la fuite tant qu'il est encore temps, il annonce qu'il sera le premier à déguerpir :
que si es honra combatir,
no es menos saber huir
cuando el tiempo lo requiere.
Aperciba, pues, cualquiera

71. Quevedo, Poesía original completa, 704, vv. 29-44. On pourra comparer le sarcasme de Médore à celui du locuteur de Lope dans La Gatomaquia, IV, vv. 83-90.

72. Luis de Góngora, "Pensó rendir la mozuela ", dans Luis de Góngora, Obras Completas, I, Antonio Carreira (éd.), Madrid, Biblioteca Castro, 2000, p. 106. 
los pies, si queréis salvaros, porque yo pienso llevaros, si puedo, la delantera ${ }^{73}$.

Certes, un chef de guerre doit savoir épargner ses hommes lorsque le prix du sang devient excessif. Ainsi, dans La Dragontea de Lope, un soldat tient à son chef le discours suivant :
¿Qué pertinacia es ésta? ¿Tú no sabes
que aventurar la gente siempre ha sido de heroicos capitanes y hombres graves, como era el duque de Alba, defendido?
Las victorias más altas y suaves que reyes y monarcas han tenido, cuando copia de sangre les costaban, trágicos vencimientos los llamaban ${ }^{74}$.

Dans les deux textes, il relève de la prudence de renoncer au combat lorsque la défaite est assurée et que les pertes humaines sont trop nombreuses. La retraite, dans ces conditions, ne semble pas infamante. Encore fautil savoir se retirer avec panache. Le capitaine de Castillejo, qui prend la poudre d'escampette, ne semble guère s'en soucier, et n'adopte pas l'attitude d'un héros épique capable de renoncer avec fierté. Pour mieux percevoir la différence entre ces personnages burlesques et ceux de La Gatomaquia, La Moschea et du Poema heroico de la necedades y locuras de Orlando, il convient d'ébaucher un bref portrait du héros idéal.

Dans le premier de ses Discorsi dell'Arte Poetica, le Tasse revient sur la théorie aristotélicienne des genres épique, tragique et comique. La comédie se distingue des deux autres genres par la bassesse des actions qu'elle imite. L'épopée et la tragédie portent toutes deux sur les actions et les hommes illustres. Mais, précise le Tasse, cette parenté ne doit pas masquer une différence essentielle : le poète tragique veut susciter la pitié et l'effroi, il met donc en scène des personnages abattus par le destin. Ces revers de la fortune peuvent frapper tout un chacun, et le personnage tragique, loin d'être le symbole d'un vice ou d'une vertu, demeurera dans une sorte de juste milieu ("persone né buone né cattive, ma d'una condizion di mezzo »). Le héros épique, en revanche, tend vers l'excellence et c'est à ce titre qu'il devient

73. Cristóbal de Castillejo, Obras de amores. Obras de conversación y pasatiempo, Jesús Domínguez Bordona (éd.), Madrid, Espasa Calpe, 1969, p. 210-211.

74. Lope de Vega, La Dragontea, Antonio Sánchez Jiménez (éd.), Madrid, Cátedra, 2007, p. 419. 
illustre ("[...] l'illustre dell'eroico è fondato sovra l'imprese d'una eccelsa virtù bellica, sovra i fatti di cortesia, di generosità, di pietà, di religione [...] »). Il possède mieux que nul autre la "vertu héroïque " qui en fait un personnage d'exception en lui conférant un lustre dont il brille pour l'éternité :

L'epico a l'incontra vuole nelle persone il sommo della virtù, le quali eroiche dalla virtù eroica sono nominate. Si ritrova in Enea l'eccelenza della pietà, della fortezza militare in Achille, della prudenza in Ulisse, $e$, per venire a i nostri, della lealtà in Amadigi, della constanza in Bradamante; anzi pure in alcuni di questi il cumulo di tutte queste virtù. E se pur talora dal tragico e da l'epico si prende per soggetto de'lor poemi la persona medesima, è da loro diversamente e con varii rispetti considerata. Considera l'epico in Ercole e in Teseo il valore e l'eccellenza dell'armi; gli riguarda il tragico come rei di qualche colpa, e perciò caduti in infelicitá ${ }^{75}$.

Cette perfection du héros épique transparaît également dans un texte de Joseph Pellicer de Tovar, Epilogo de los preceptos del poema heroico. Escrito en la Academia de Madrid (1625). Elle est à la fois physique et morale, le personnage devant être beau, courageux, avisé, habile et sage

Debe [...] ser este héroe señor soberano en quien concurran todas las perfecciones morales que deseó Jenofonte a Ciro, Aristóteles a Alejandro, hermoso, valiente, intrépido, sabio, prudente, cuerdo, político, maduro, experimentado, religioso, justo, clemente, liberal, magnánimo, vigilante, severo, astrólogo, astrónomo, geógrafo, piloto, táctico, matemático y versado en las lenguas y ciencias, de noticias, agilidad y destreza sobre todas las personas que introduce, para que tenga fin bienaventurado $y$ glorioso ${ }^{76}$.

L'ethos du héros épique rejoint ainsi pour l'essentiel l'ethos du chevalier, tel qu'il apparaissait, par exemple, dans les Partidas du roi Alphonse le Savant ("Que los defensores deben ser entendidos", "Que los caballeros deben ser sabidores [...]", "Que los caballeros deben ser bien acostumbrados", "Como deben los caballeros ser arteros e mañosos ") ${ }^{77}$.

75. Torquato Tasso, op. cit., p. 12.

76. Ce texte peut être consulté dans Alberto Porqueras Mayo, La teoría poética en el Manierismo y Barroco españoles, Barcelona, Puvill Libros, 1989, p. 166-169 (p. 168 pour ma citation).

77. Alfonso el Sabio, Las siete partidas del sabio rey don Alfonso el IX, con las variantes de más interés y con la glosa del lic. Gregorio López, I. Sanponts y Barba, R. Marti de Eixala, J. Ferrer y Subirana (éds.), Barcelona, Imprenta de A. Bergnes, 1, 1843, p. 853-854 (Partida II, título XXI, 5, 6, 7, 8). 
Les principaux personnages de Lope de Vega, Quevedo et Villaviciosa participent d'un ethos analogue à celui qui vient d'être brièvement envisagé. Ils appartiennent à une élite constituée en caste et qui obéit à ses règles. Les chats de La Gatomaquia sont nobles et revendiquent le prestige de leurs ascendants. Marramaquiz se prétend " noble al doble / de todo gato de ascendiente noble ", et le locuteur enjoint à Zapaquilda de se montrer moins cruelle à l'égard d'un amant qui fait preuve de noblesse autant que de sagesse ${ }^{78}$. Cette noblesse transparaît dans le courage des personnages. Ainsi, Quevedo attribue à Ferragus une "superlative vaillance » (I, v. 190). C'est probablement la principale vertu de Marramaquiz, "no menos [...] prudente que valiente ", "robusto y valiente ", "el más valiente / que han visto los tejados desta villa", "el gato más discreto y más valiente " ${ }^{79}$. Une façon de revendiquer ce courage et cette noblesse consiste à en déposséder l'ennemi en lui attribuant roture et lâcheté ("villanos descorteses, / más falsos y traidores I que moros y holandeses ", "junta de gatos viles, I que no de bien nacidos", "gato bárbaro y cobarde", " cobardes y abatidos", "Micifuf cobarde ", "Gallina Micifuf ", "escuadrón de gallinas " ${ }^{80}$ ). L'étude de ces champs sémantiques montre que Villaviciosa les utilise de manière analogue dans La Moschea ("Mostró el rey Granestor su noble uso / de estimar el valor que se le humilla", "Yo me nombro / el crudo azote del pulgón villano", "Mejor fuera mil veces, mejor fuera I de valiente cobrar rico renombre ", " $O O h$, miserable joven, más valiente / que fue contra los dárdanos Aquiles, / Ulises sagacísimo y prudente I contra la red de las arañas viles ", "importa mucho un capitán valiente, I que es belicosa la contraria gente ", "descarguen sus cóleras adustas / nubes de flechas [...] / contra la vil canalla", "Hoy, gente vil, me pagaréis la afrenta", "Gentes infames, dijo, gentes viles / hoy quedaréis sin vida en la batalla" $)^{81}$. La violence verbale que supposent de telles insultes ne doit pas être sousestimée. Dans son Discurso en orden a reformar la Ley del Duelo, le comteduc d'Olivares considère qu'un noble qualifié de villano doit se défendre sur-le-champ. Par ailleurs, comme l'explique Claude Chauchadis, Olivares estime que "seul un duel sur cent mérite $[. .$.$] d'être mené à son terme :$

78. La Gatomaquia, III, v. 256 et suivants, VI, v. 206. Voir également le discours de Micifuf, III, vv. 205 et suivants.

79. La Gatomaquia, III, vv. 146 et 191 ; VI, vv. 353-354 ; VII, v. 380. Micifuf est également qualifié de valiente (I, v. 266 ; III, v. 11 ; VI, v. 38). Cette caractéristique lui est attachée dès le sonnet liminaire (p. 69).

80. La Gatomaquia, III, vv. 233 et 252 ; V, vv. 264 et suivants ; V, v. 359 ; VI, vv. 174, 290. Cette liste n'est évidemment pas exhaustive.

81. La Moschea, VII, vv. 413-414; X, vv. 453-44; II, vv. 341-342; III, vv. 273-276; VII, vv. 471-472; III, vv. 629-631; VI, v. 341; VI, vv. 481-482. 
celui d'un homme qui veut prouver son courage contre un adversaire qui l'a accusé de lâcheté ${ }^{82}$. Nos héros revendiquent leur noblesse et leur courage sans failles. Appartenir à cette caste d'hommes bien nés impose de respecter certaines règles par lesquelles le personnage manifeste son adhésion à l'ethos des héros chevaleresques. Le respect des lois fixées fait partie de ces règles car il engage la parole donnée. On peut ainsi lire dans les Partidas d'Alphonse le Savant : "Otrosi que las palabras que dixesen jurando, o haciendo homenaje, y prometiendo de hacer alguna cosa que la guardasen [...]»; «[...] deben ser leales e firmes en lo que hicieren ca la lealtad les hará guardar de yerro, e la firmedumbre hará que non sean movedizos de uno a al [...]" ${ }^{83}$. Dès lors qu'un chevalier participe à un tournoi, il accepte implicitement de se soumettre aux règles qui président à son déroulement, surtout si elles ont été spécifiées par le souverain lui-même. Dans La Moschea, le roi réunit tous les chevaliers pour leur indiquer dans quel ordre et de quelle manière ils devront entrer en lice :

$$
\begin{aligned}
& \text { ¡Qué máquina de fuertes caballeros } \\
& \text { van entrando en la corte aventureros! } \\
& \text { [...] } \\
& \text { Túvolos juntos en su sala un día } \\
& \text { el rey, que quiso darles muy despacio } \\
& \text { el orden del torneo, el modo y traza } \\
& \text { de entrar en él y de ocupar la plaza }
\end{aligned}
$$

Le tournoi annoncé au lecteur semble ainsi soumis à une étiquette, il revêt un caractère cérémonial et doit constituer, comme tous les tournois, une fête célébrant la chevalerie. Dans le Poema heroico de las necedades y locuras de Orlando el enamorado, la venue d'Angélique perturbe les joutes organisées par Charlemagne. S'y substituent d'autres joutes, à la demande d'Angélique qui offre sa main à celui qui parviendra à vaincre son frère Argail. Mais, si celui-ci fait tomber son adversaire, ce dernier devra s'avouer vaincu

82. «[...] le comte-duc étudie le cas particulier des insultes verbales telles que judío (juif), villano (vilain) pour le noble, borracho (ivrogne), etc. Il estime que lorsque celles-ci sont prononcées en présence de la personne, cette dernière doit s'en défendre sur-le-champ, car une absence de réaction équivaudrait à un consentement qui la rendrait infâme et inapte à se venger par la suite ", Claude Chauchadis, "Noblesse, pouvoir et duel : les débats autour du discours d'Olivares contre la loi du duel (1638) », dans Jean-Pierre Amalric (sous la dir. de), Pouvoirs et société dans l'Espagne moderne, Toulouse, Presses Universitaires du Mirail, 1993, p. 77-87.

83. Alfonso el Sabio, op. cit., p. 863 (Partida II, título XXI, ley 22). Je modernise l'orthographe.

84. La Moschea, II, vv. 295-304. 
(I, vv. 553-568). Ferragus, en refusant de reconnaître sa défaite, encourt le blâme, comme le lui rappelle Argail : "Contra toda razón -dijo Argalía- I quebrantas los capitulos honestos; / date a prisión, pues el concierto ha sido / que quede prisionero el que ha caido.» ${ }^{85}$ Plus loin, Argail affirme qu'il sait observer les lois de la chevalerie (" [... sé guardar la ley de caballero», II, v. 332). C'est indéniablement le personnage le plus attaché à ces lois, bien qu'il en use pour détruire la cour de Charlemagne. Sa voix porte l'ethos chevaleresque dans un univers où il est menacé.

L'esprit de caste commande aussi aux héros de La Gatomaquia de rentrer leurs griffes lorsque l'alguazil vient les séparer : "Mas como respetar a la justicia / de gente principal respeto sea, / y lo contrario bárbara malicia, I luego Marramaquiz rindió la espada. " L'ethos chevaleresque impose également de réparer tout affront. C'est ce que le locuteur de La Gatomaquia déclare : "[...] a un pecho noble, a un inclito sujeto, I mayor obligación, más celo alcanza I de poner en efeto / desempeñar su honor con la venganza.» ${ }^{87}$ Cette vengeance ne peut passer ni par les tribunaux, ni par le poison. Le sang doit couler : " $S i$ aquesta injuria ha de quedar vengada, / remitase a la pólvora o la espada.» ${ }^{88}$

De même, c'est pour venger l'affront fait au roi Sanguileón que Matacaballo veut mener la guerre contre les fourmis (La Moschea, III, vv. 517-520). Enfin, pendant le combat final, le roi des araignées rappelle à l'ordre les fourmis, et les encourage à venger la mort de leur souverain, abattu par le roi des mouches :

\author{
¿Qué locura soberbia y temeraria \\ la fuerza en vuestros ánimos ahuyenta \\ sin poneros delante vuestra afrenta? \\ Ya llega mi zancuda compañia \\ con cuyas balas en espacio breve \\ castigaré la grande alevosía \\ de ese enemigo mosca, de ese aleve. (XII, vv. 430-436)
}

85. Poema heroico de las necedades y locuras de Orlando el enamorado, II, vv. 301-304. Voir également II, vv. 222-224 pour un rappel à l'ordre analogue.

86. La Gatomaquia, III, vv. 348-351.

87. La Gatomaquia, II, vv. 206-209.

88. La Gatomaquia, VI, vv. 393-394. Voir également les vers qui précèdent ce distique et III, vv. 230-238. De même, l'un des personnages de La Muracinda, poème héroï-comique légèrement antérieur à ceux étudiés ici, déclare : "Un agravio de honor no se perdona / ni satisface sin letal castigo" (Juan de la Cueva, Fábulas mitológicas y épica burlesca, José Cebrián García (éd.), Madrid, Editora Nacional, 1984, p. 216 (vv. 421-422)). Les héros de ce poème sont des chats, des chiens et des taureaux. 
Les actes de bravoure de ces personnages ne constituent pas les seules manifestations de leur adhésion à un même ethos. Leurs discours montrent combien ils maîtrisent la rhétorique des héros. Villaviciosa affirme que toute l'éloquence de Caton est peu de chose quand Sicaborón s'exprime, et Lope précise que Micifuf, bien que chat, parlait comme Cicéron ${ }^{89}$. Les harangues que ces deux personnages adressent à leurs soldats doivent les encourager à gagner par les armes une gloire éternelle :

Es la virtud del hombre

la que le inclina a los ilustres hechos;

digna es la fama de valientes pechos.

Hoy habéis de ganar glorioso nombre [...] (La Gatomaquia, VII, vv. 245-248).

\author{
Ya, Quirites moscones, [...], llega \\ el rico y venturoso tiempo cuando \\ se ha de mostrar en la marcial refriega \\ la virtud interior de nuestro bando. \\ Ya el nombre singular que el ocio os niega \\ cobrar podréis ahora peleando, \\ dejando siempre vuestra fama viva \\ si el hado inicuo de la vida os priva. (La Moschea, X, vv. 233-240).
}

Par ces discours, les personnages prouvent qu'ils n'excellent pas que dans le maniement des armes, et qu'ils maitrisent également la rhétorique des héros, reflet d'une pensée et d'un imaginaire dans lesquels le camp du juste ne peut qu'être le camp vainqueur. Par ces discours, ils se projettent audelà d'une victoire qu'ils croient certaine et assurent à leurs troupes une renommée éternelle et conquise de la meilleure manière : par les armes. L'ethos chevaleresque ne transparaît donc pas uniquement dans la parole donnée mais aussi dans l'usage qui est fait de la parole comme logos. Seul Ferragus se distingue en ne reconnaissant que la force brutale, qu'il considère comme la véritable rhétorique des héros. "No me gastes arenga cortesana", "en cuanto dices mientes todo entero ", déclare-t-il à Argail, également qualifié de "caballerito del Padrón del Pino $»^{90}$. Ferragus identifie le discours à une forme de mollesse incompatible avec les valeurs guerrières qui l'animent. Dans le poème quévédien, Astolphe est l'archétype de cette mollesse qui

89. La Moschea, X, vv. 217-224 ; La Gatomaquia, VII, v. 234. Le passage de Villaviciosa compare également le héros à Cicéron.

90. Poema heroico de las necedades y locuras de Orlando el enamorado, II, vv. 317, 525, 342. Voir également les vers 349-352. 
transparaît dans le raffinement excessif et la couardise ${ }^{91}$. Il est un antihéros qui représente la fin de l'époque des chevaliers. Lorsqu'il découvre la lance d'Argail, il s'en saisit dans l'espoir d'en tirer un bon prix : " no la pienso probar en los guerreros : / antes pienso romperla en los plateros " ${ }^{92}$. Ces mots d'Astolphe font de ce personnage le symbole de la fin d'une ère et de l'anéantissement d'un ethos que Roland et Roger s'employaient à faire survivre en se débarrassant de l'arquebuse et du bouclier enchanté (Orlando Furioso, IX et XXII). Astolphe est ridicule, d'un ridicule qui rappelle celui qui frappe le roi Sanguileón lorsqu'il fait son apparition dans La Moschea. Souverain faible, efféminé, vain et qui ne se soucie guère des maux de ses sujets, Sanguileón ne songe qu'aux plaisirs et perd l'esprit en apprenant que les fourmis attaquent ${ }^{93}$. Son comportement change du tout au tout lorsque apparaît Matacaballo, son beau-frère. Ce personnage est un modèle de vertu qui possède le courage et la sagesse dont est initialement dépourvu Sanguileón ${ }^{94}$, qu'il exhorte à se montrer digne de son rang :

\author{
Nosotros, a quien dio naturaleza \\ el nombre incomparable de varones \\ tenemos de mostrar la fortaleza \\ que encierran nuestros bravos corazones. \\ Si somos la columna y la cabeza \\ que sustentamos nuestras dos naciones, \\ no es bien que las cabezas desfallezcan, \\ no se mueran los miembros y perezcan. (III, vv. 417-424)
}

Sanguileón décide alors de lever les troupes nécessaires au combat et de partir à la conquête du pays des fourmis. Par ce sursaut épique, il rachète sa conduite passée en assumant pleinement ses fonctions de chef de guerre (" [...] os trujeron los dioses por reparo / de mi persona y reino [...]», III, vv. 547-548).

91. Poema heroico de las necedades y locuras de Orlando el enamorado, II, vv. 49-182. L'ardeur belliqueuse du cheval d'Astolphe contraste avec la pusillanimité du personnage.

92. Poema heroico de las necedades y locuras de Orlando el enamorado, II, vv. 607-608. Dans sa thèse (p. 184), Pablo Lombó écrit à propos de ces vers: "Caracterizan la cobardía y la codicia de Astolfo, que considera la lanza un objeto con valor económico".

93. Tous ces reproches apparaissent dans le chant II, en particulier aux vers 137-140, 337 464 et 515. Consulter l'introduction de Ángel Luis Luján (p. 79-83) pour l'étude de la satire dans le poème et une judicieuse comparaison avec la Epistola satírica y censoria de Quevedo.

94. Par ailleurs, il possède également une autre vertu cardinale, la justice, qui le pousse à quitter son royaume pour voler au secours de Sanguileón (III, vv. 177-200, ainsi que 381384). 
À la mollesse de ces deux personnages s'oppose l'extrême audace de Ferragus et Sicaborón. C. Sabor de Cortázar avait évoqué la parenté qui semble les unir ${ }^{95}$. Tous deux sont assimilés à des démons ${ }^{96}$ qui parlent moins qu'ils ne vocifèrent ${ }^{97}$ et qui, non contents de se battre contre d'autres personnages, défient littéralement le cosmos. Ainsi, lors de la tempête qui menace la flotte des mouches, Sicaborón prétend frapper les éléments qui se déchaînent :

"Canalla ", al viento dice, "vil, bastarda,
ejercitada siempre en obras viles,
heridos volveréis a vuestra gruta
por el espada del señor de Buta".
A todas partes con furor esgrime
vomitando blasfemias por la boca
y cuando más el huracán le oprime
más a cólera y rabia se provoca.
No queda cosa, al fin, que no lastime
del fiero viento la soberbia loca.
Mas éste con mil votos y reniegos
vomita contra el aire vivos fuegos

Et Ferragus, constatant qu'Angélique a disparu, veut lutter contre le ciel, les Enfers et la mer :
Si al cielo con Mahoma te has subido
[...], yo bajaré a la tierra el cielo ;
si acaso en los infiernos te has sumido, no se le cubrivá al infierno pelo ;

95. La Gatomaquia, p. 23. Sicaborón me fait également songer à un autre personnage de la geste de Roland : Mandricard, le païen roi des Tartares. Sicaborón est lui aussi roi des Tartares, et cette qualité apparait fréquemment. Le locuteur précise également qu'il est païen (le syntagme «tártaro pagano" apparaît dans X, v. 1 ; XI, vv. 606 et 610 ; XII, v. 851).

96. Dans le Poema heroico de las necedades y locuras de Orlando el enamorado Ferragus est qualifié de "guerrero endemoniado" (I, v. 6), "diablo, u caballero andante " (II, v. 222), " diablo desatado en todo », (II, v. 240), "un demonio con gestos de Ganassa ", (II, v. 430), " ese endemoniado ", (II, v. 454). Pour Sicaborón, voir La Moschea, VII, vv. 455, 465-466 ; XII, vv. 551,640 .

97. La Moschea, V, vv. 298 et 304 ; Poema heroico de las necedades y locuras de Orlando el enamorado, II, v. 543 (toutes ces citations ne prétendent évidemment pas constituer une liste exhaustive).

98. La Moschea, V, vv. 293-304. Comparer avec V, vv. 245-248 et vv. 517-528. 
si en el profundo mar te has zabullido, con el fuego que exhalo enjugarélo; si los diablos te llevan en cadena, tras ellos andaré, marido en pena. (II, vv. 545-552)

Ferragus et Sicaborón sont dotés d'une audace extrême, ce qui en fait des personnages parfaitement dignes du poème épique. Mais ils ne se dominent pas et il leur manque ce sens de la maîtrise de soi que doit posséder le héros chevaleresque ${ }^{99}$. Aussi, ils ne parviennent pas à contenir la passion qui les anime et dont la nature les distingue. Sicaborón est en proie à une constante colère. Son irascibilité transparaît dans la réaction que déclenchent quatre puces en lui refusant l'hospitalité :

\author{
La sangre helada, con la furia hambrienta \\ en cólera se enciende y el enojo \\ al furibundo tártaro atormenta \\ por ver su acero en sangre aleve rojo. \\ "Hoy, gente vil, me pagaréis la afrenta", \\ dijo, "si de las vidas os despojo, \\ y que me deis hará la fuerza mía \\ lo que no pudo hacer la cortesía». (VI, vv. 337-344)
}

L'affront provoque le courroux du héros, la force étant présentée comme l'alternative nécessaire lorsque la courtoisie ne suffit pas. On a là un discours en accord avec les règles de la chevalerie ${ }^{100}$. Contrairement à Sicaborón,

99. Rappelons que pour Alphonse le Savant, le chevalier doit posséder les quatre vertus cardinales. "Ca la cordura les hará que lo sepan guardar a su pro e sin su daño. E la fortaleza que estén firmes en lo que hicieren, e no sean cambiadizos. E la mesura que obren de las cosas como deben e no pasen a más. E la justicia, que la hagan derechamente». Alfonso el Sabio, op. cit., p. 853 (Partida II, Título XXI, ley 4).

100. Pour la colère et la cruauté de Sicaborón, voir VI, vv. 497-500 et, au dernier chant, le combat qui voit la mort du héros (en particulier les vers 529-552). À propos de ce personnage, Ángel Luis Luján Atienza écrit, p. 33-34 de son édition: « [...] este personaje se ajusta a los moldes de lo grotesco, según lo define Bajtín (desmesura, relación con la bebida y la comida, etc...), lo que nos puede dar la clave sobre la interpretación de todos estos personajes no como anti-héroes sino como aproximaciones al héroe grotesco, que no invierte lo heroico sino que lo asimila en su naturaleza contradictoria». Luján Atienza considère à fort juste titre que « la epopeya paródica se convierte en una inversión, no de la cualidad de lo heroico, sino de los portadores de ella ", p. 33. Felipe Pedraza a également recours à la notion de grotesque lorsqu'il évoque la Gatomaquia: "La pose heroica se reduce a lo grotesco. Los héroes clásicos [...] se han dado un garbeo por los espejos deformantes del callejón del Gato», El universo poético de Lope de Vega, p. 236. 
Ferragus pâtit d'une libido incontrôlable ${ }^{101}$ qui le mène à enfreindre ces règles. Mais son comportement n'est pas anti-héroïque. C'est Astolphe qui représente l'anti-héroïsme à la Cour de Charlemagne, son discours et son attitude en font un personnage éthiquement analogue au Médore du romance quévédien Burla el poeta de Medoro, y Medoro de los pares. Dans le Poema heroico de las necedades y locuras de Orlando el enamorado, l'ethos des héros semble vénérable et ridicule à la fois. Il est vénérable parce qu’il renvoie à un Moyen Âge austère, quand l'oisiveté ne venait pas corrompre la vertu et que le luxe n'amollissait pas les âmes. Mais, en même temps, il est ridicule car le sens de l'honneur et l'amour courtois paraissent bien désuets, voire anachroniques, à la " cour carnavalesque » de Charlemagne. Le regard porté par Quevedo sur cet univers est à la fois nostalgique et amusé, les codes de la chevalerie apparaissant comme une manière de contenir avec panache les réactions purement instinctives de Ferragus ou des personnages attablés pour le banquet du chant I. Il y a, dans le traitement qui est fait de l'héroïsme des personnages quévédiens, une part de sarcasme plus apparente que dans les vers de $L a$ Moschea et La Gatomaquia, dont l'ambiguïté tient essentiellement au fait que ces héros soient des animaux.

\section{Conclusion}

Les gestes burlesques de Villaviciosa, Lope de Vega et Quevedo, tout comme La Muracinda de Juan de la Cueva, ne vont pas à rebours de l'héroïsme de l'épopée. Les principaux personnages recherchent le péril et la prouesse car ils considèrent que c'est dans l'exploit qu'ils se révèlent tout entiers. La figure du anti-héros ne peut donc qu'être secondaire dans ces poèmes. C'est dans le roman picaresque ainsi que dans des poèmes comme Felicidad barata y artificiosa del pobre ou Burla el poeta de Medoro, y Medoro de los pares ${ }^{102}$ que le lecteur découvre le discours d'un débrouillard sans vergogne à mille lieues de la figure du héros. Quevedo élabore aussi des compositions dans lesquelles le locuteur renonce à toute ambition au profit de plaisirs simples. Il en va ainsi, par exemple, dans "Volver quiero a vivir a trochimoche ", ou La vida poltrona ${ }^{103}$, qui véhiculent également un ethos fort éloigné de celui qui anime les personnages des trois gestes burlesques étudiées ici, soucieux de se forger un destin. Construire une épopée burlesque

101. Poema heroico de las necedades y locuras de Orlando el enamorado, I, v. 497; II, vv. 313315, 524, 534, 553-560.

102. Quevedo, Poesia original completa, 529 et 704.

103. Quevedo, Poesía original completa, 596 et 773. 
sur l'anti-héroïsme des personnages aurait d'ailleurs relevé de la gageure. En effet, on voit mal comment le récit aurait pu conserver son caractère épique avec des protagonistes qui refusent l'action et le risque inhérents à l'epos. Les poètes burlesques du Siècle d'Or choisissent de créer de véritables héros et de les lancer dans des aventures dignes de l'épopée. Mais ces aventures sont celles de chats, de moustiques ou de chevaliers qui évoluent dans un univers carnavalesque. Quelles conclusions en tirer quant à la signification de ces œuvres pour l'histoire de l'épopée?

Dans son ouvrage sur la poésie épique dans l'Espagne du Siècle d'Or, Frank Pierce montre que ce genre culmine sur la période qui s'étend de 1580 à 1630. Concrètement, entre 1615, année de publication de La Moschea, et 1638, date à laquelle Quevedo écrit à Sancho Sandoval en lui demandant de récupérer auprès de l'un de ses amis " unas octavas de las Locuras de Orlando $[\ldots]^{104}{ }^{\prime}$, Frank Pierce dénombre cinquante poèmes épiques. Maxime Chevalier a montré que ce triomphe de la poésie épique était contemporain d'une certaine désaffection pour la littérature chevaleresque. Celle-ci montrait " une image sublimée de la société aristocratique " que les lecteurs du seizième siècle observaient avec nostalgie, mais qui semblait définitivement anachronique à ceux du début du dix-septième ${ }^{105}$. Il est probable que le travestissement du poème de Boiardo, tout comme la geste des chats, constituent des indices du regard ironique porté sur l'univers du romanzo. De même, transformer d'infimes insectes en héros implique une mise à distance caustique de l'héroïsme. Ces poèmes invitent le lecteur à une contemplation amusée. Toutefois, loin d'illustrer un quelconque "crépuscule de l'épopée " ${ }^{106}$, La Moschea et La Gatomaquia prolongent dans le domaine du burlesque l'héroïsme propre au genre et sont un signe de l'efficacité poétique qui lui est encore reconnue. Ils ne prennent pas le contrepied d'une idéologie aristocratique et guerrière. L'enthousiasme belliqueux des personnages, ou la description de troupes dont la fière allure vient

104. Je m’appuie là encore sur la thèse de Pablo Lombó, p. 32-33. Pierce fait la liste des poèmes épiques espagnols publiés entre 1550 et 1700 aux pages 327-366 de : Frank Pierce, La poesía épica del siglo de oro, Madrid, Gredos, 1961.

105. Maxime Chevalier, Lectura y lectores en la España del siglo XVI y XVII, Madrid, Turner, 1976, p. 65-103. L'auteur évoque plus loin «el prestigio de que gozaron en los últimos decenios del siglo XVI y los primeros del siglo siguiente no sólo La Araucana y las epopeyas de Lope, sino también otros poemas hoy tan olvidados como La segunda parte de Orlando de Nicolás Espinosa, el Carlo Famoso de Luis Zapata, La Austríada de Juan Rufo o El León de España de Pedro de la Vecilla Castellanos", p. 136-137.

106. Je reprends l'expression de Daniel Madelénat, qui intitule ainsi un chapitre consacré à l'épopée du dix-neuvième siècle. 
magnifier le paysage ${ }^{107}$, animent ces poèmes burlesques d'un souffle épique. Les lecteurs du dix-septième siècle, sensibles à la hiérarchisation des genres, devaient néanmoins considérer foncièrement ambigu le fait d'attribuer cet héroïsme à des animaux. L'ambiguïté est plus grande encore dans le poème de Quevedo. En effet, Ferragus est un personnage en rupture avec le monde chevaleresque, il refuse une soumission aveugle à un ethos dont il récuse la vaine rhétorique, mais c'est ainsi qu'il déjoue le piège tendu par Argail pour venir à bout de chaque paladin. Paradoxalement, c'est en enfreignant la règle que Ferragus crée les conditions de la survie d'un ethos chevaleresque dont la seule manifestation, à ses yeux, passe par les armes.

Cette ambiguïté inhérente aux trois poèmes garantissait leur succès. Ils n'offraient pas seulement aux lecteurs des œuvres qui reposent sur la transformation ludique d'un genre prisé et peuplé d'aristocrates héroïques. Ils rencontraient l'ethos du lecteur sur un autre terrain, celui du courtisan qui brille par sa subtilité, par sa capacité à faire preuve d'esprit pour rendre l'inconvenant convenable et même appréciable, aspect essentiel de la poétique du burlesque. Un propos vulgaire, sordide ou même, plus simplement, un peu léger, était socialement valorisé dès lors que son auteur l'exprimait avec esprit, en jouant par exemple sur la bisémie ou sur l'implicite. Il s'agissait en fait d'appliquer aux vers inspirés par la muse Thalie les préceptes formulés par Gracián dans son Agudeza y arte de ingenio, et notamment le «significar a dos luces " ${ }^{108}$. Indépendamment du registre choisi, burlesque ou sérieux, la pointe confère au discours une sorte de plus-value sociale dès lors qu'elle inonde le discours. C'est en partie pour cela qu'en 1637 une académie burlesque put se tenir publiquement devant le roi Philippe IV et que, parmi les juges, figurait le Prince d'Esquilache ${ }^{109}$. Villaviciosa, Lope de Vega et

107. Pour cette représentation des troupes, voir par exemple, La Gatomaquia, VII, vv. 1-52 ou La Moschea, chant IV, en particulier les vers 97-124 et 393-400. L'enthousiasme qui anime les personnages, tout comme la représentation d'une armée haute en couleur et qui constitue un spectacle à la fois visuel et auditif, transparaissent dans ces épopées burlesques comme dans les épopées sérieuses en dépit des différences esthétiques propres à ces poèmes. On pourra comparer ces passages avec la description de la flotte de Drake au deuxième chant de la Dragontea (notamment vers 857-912) ou celle de l'armée levée par Rostubaldo dans $\mathrm{La}$ Hermosura de Angélica (XII, vers 289-432).

108. Consulter, par exemple, le discours intitulé « De los ingeniosos equivocos » dans Baltasar Gracián, Obras completas, II, Emilio Blanco (éd.), Madrid, Turner, 1993, p. 575-583. Sur ces questions, lire également Mercedes Blanco, Les Rhétoriques de la pointe. Baltasar Gracián et le conceptisme en Europe, Paris, Honoré Champion, 1992 ; Maxime Chevalier, Quevedo y su tiempo. La agudeza verbal, Barcelona, Crítica, 1992 et Anthony Close, Cervantes and the comic mind of his age, Oxford, Oxford University Press, 2000.

109. María Teresa Julio, Academia Burlesca que se hizo en Buen Retiro a la Majestad de Filipo 
Quevedo s'adressent au même public que les auteurs d'épopées sérieuses, ils comptent sur sa familiarité avec à la fois le genre épique et l'esthétique de la pointe pour réaliser une lecture attentive aux accents polyphoniques du texte. Ces auteurs confèrent ainsi une légitimité poétique aux braillements de Ferragus, aux combats de chats et à la discipline presque militaire des fourmis en invitant le lecteur à contempler les héros avec amusement tout en percevant en eux le reflet d'une ardeur guerrière et d'une activité littéraire empreintes de noblesse. La geste burlesque peut ainsi être lue comme une application de ce "significar a dos luces " préconisé par Gracián car, derrière la voix et le projet ouvertement burlesques, l'énonciation demeure toujours guidée par la rhétorique des héros.

Cuarto el Grande año de 1637, Madrid, Frankfurt-am-Main, Iberoamericana, Vervuert, 2007, p. 20 et 48. On voit combien le registre burlesque était prisé et valorisé dans le fait même que cette académie se soit tenue dans le cadre d'une semaine de festivités solennelles motivées par l'accession de Fernando III au titre d'Empereur du Saint-Empire Romain Germanique. 